\title{
What Do We Know about Candida auris? State of the Art, Knowledge Gaps, and Future Directions
}

\author{
Victor Garcia-Bustos ${ }^{1,2,3, *}$, Marta D. Cabanero-Navalon ${ }^{1, *}$, Amparo Ruiz-Saurí ${ }^{3}$, Alba C. Ruiz-Gaitán ${ }^{2}\left({ }^{1}\right.$, \\ Miguel Salavert ${ }^{1,2}$, María Á. Tormo ${ }^{2}$ and Javier Pemán ${ }^{2,4}$ \\ 1 Department of Internal Medicine and Infectious Diseases, University and Polytechnic La Fe Hospital, \\ 56026 Valencia, Spain; salavert_mig@gva.es \\ 2 Severe Infection Research Group, Health Research Institute La Fe, 46026 Valencia, Spain; \\ albacruiz@gmail.com (A.C.R.-G.); tormo_man@iislafe.es (M.Á.T.); peman_jav@gva.es (J.P.) \\ 3 Department of Pathology, Faculty of Medicine and Dentistry, University of Valencia, \\ 46010 Valencia, Spain; amparo.ruiz-sauri@uv.es \\ 4 Department of Medical Microbiology, University and Polytechnic La Fe Hospital, 46026 Valencia, Spain \\ * Correspondence: victorgarciabustos@gmail.com (V.G.-B.); marta.dafne.cabanyero@gmail.com or \\ cabanero_marnav@gva.es (M.D.C.-N.); Tel.: +34-696684551 (V.G.-B.); +34-626820457 (M.D.C.-N.)
}

\section{check for} updates

Citation: Garcia-Bustos, V.; Cabanero -Navalon, M.D.; Ruiz-Saurí, A.; Ruiz-Gaitán, A.C.; Salavert, M.; Tormo, M.Á.; Pemán, J. What Do We Know about Candida auris? State of the Art, Knowledge Gaps, and Future Directions. Microorganisms 2021, 9, 2177. https://doi.org/10.3390/ microorganisms 9102177

Academic Editors: Michae K. Mansour and László Majoros

Received: 20 September 2021 Accepted: 13 October 2021 Published: 19 October 2021

Publisher's Note: MDPI stays neutral with regard to jurisdictional claims in published maps and institutional affiliations.

Copyright: (c) 2021 by the authors. Licensee MDPI, Basel, Switzerland. This article is an open access article distributed under the terms and conditions of the Creative Commons Attribution (CC BY) license (https:// creativecommons.org/licenses/by/ $4.0 /)$.

\begin{abstract}
Candida auris has unprecedently emerged as a multidrug resistant fungal pathogen, considered a serious global threat due to its potential to cause nosocomial outbreaks and deep-seated infections with staggering transmissibility and mortality, that has put health authorities and institutions worldwide in check for more than a decade now. Due to its unique features not observed in other yeasts, it has been categorised as an urgent threat by the Centers for Disease Control and Prevention and other international agencies. Moreover, epidemiological alerts have been released in view of the increase of healthcare-associated C. auris outbreaks in the context of the COVID-19 pandemic. This review summarises the current evidence on C. auris since its first description, from virulence to treatment and outbreak control, and highlights the knowledge gaps and future directions for research efforts.
\end{abstract}

Keywords: Candida auris; candidaemia; virulence; pathogenesis; epidemiology; diagnosis; antifungal agents; outbreak

\section{Introduction}

The genus Candida is composed of approximately of 200 species. It is the most important fungal genus in the medical field [1], as some Candida species are the main cause of worldwide invasive fungal infections (IFI) [2,3]. Candida albicans, Candida glabrata, Candida parapsilosis, Candida dubliniensis, Candida tropicalis, and Candida krusei are the most frequently isolated species in patients with IFI. Nevertheless, since its first description in 2009, a new Candida species that has simultaneously emerged in the five populated continents as a new and serious public health threat has ended up accounting for most of the Candida isolates [4,5] and IFI in some regions [6-9]: Candida auris.

C. auris is an emergent species which, as a consequence of its multidrug resistance to common antifungals [10-12], difficult identification with conventional biochemical microbiological techniques [13,14], high transmissibility, surface survival [15], and environmental adaptability $[16,17]$, has been associated with serious nosocomial IFI with high mortality and is extremely difficult control in many countries [11,16,18-20].

All of these characteristics make it conspicuously different from the rest of the Candida species, and it constitutes the only fungal species able to be intrinsically resistant to the three main antifungals used in medical practice, namely azoles, amphotericin $B$, and even the first-choice agents for Candida invasive infections: echinocandins. In fact, in 2019, the Centers for Disease Control and Prevention of the United States (CDC) considered C. auris 
infection an urgent threat for international public health in the field of multidrug resistant microorganisms [21,22]. Moreover, in our actual context of the SARS-CoV-2 pandemic, its incidence seems to be increasing due to outbreaks in specialised COVID-19 treatment units [23-31].

\section{Importance and Chronology of $C$. auris Emergence}

C. auris was first isolated in the ear of a Japanese patient with external otitis in 2009 [6]. Since then, hospital outbreaks and IFI caused by this species have been described in more than 40 countries in the five populated continents, creating a global health problem. Due to its high multidrug resistance, transmissibility, ability to indefinitely colonise patients, and long persistence in the hospital environments, it has alerted the health authorities and health organisations of America and Europe.

In June 2016, the CDC communicated an extraordinary clinical alert, warning U.S. health institutions of the global emergence of $C$. auris and its capacity to cause serious IFI outbreaks in U.S. health centres [32]. Only one week after this CDC warning, Public Health England announced the isolation of this pathogenic fungus in hospitals in the United Kingdom, and reported a non-controlled outbreak of nosocomial candidaemia in the Royal Brompton Hospital in London [33], which preceded the notification in Spain of the largest European outbreak in Valencia, in the University and Polytechnic Hospital La Fe.

In October of that same year, the Pan American Health Organization (PAHO/WHO) also issued warnings about $C$. auris, and issued a new epidemiological alert about the risk of new nosocomial outbreaks in Latin America, recommending that Member States build capacity for early detection and effective reporting to prevent and control its spread in health services [34]. At the end of December 2016, when the nosocomial outbreaks in London and Valencia affected almost 100 patients, the European Centre for Disease Prevention and Control (ECDC) warned of the emergence of C. auris in Europe, and published a Rapid Risk Assessment update, appraising the risk for its spread in hospitals in European Union and European Economic Area (EU/EEA) countries [32].

Since then, the frequency of notifications of IFI due to $C$. auris has been increasing worldwide. In 2019, in the Report on Urgent Threats from the CDC, C. auris was again categorised as one of the main urgent threats, together with carbapenem-resistant Acinetobacter baumanii and Enterobacteriaceae, Clostridioides difficile, and Neisseria gonorrhoeae, with priority over other well-known resistant pathogens such as Enterobacteriaceae with extended-spectrum beta-lactamase (ESBL) production, methicillin-resistant Staphylococcus aureus (MRSA), and multidrug resistant Pseudomonas aeruginosa [21].

Recently, the use of personal protective equipment (PPE) in the SARS-CoV-2 pandemic has not helped to control C. auris transmission. In fact, many $C$. auris outbreaks have been described in COVID-19 units, both in critically ill units and conventional hospital wards. Until now, outbreaks have been identified in the USA [23,24], Italy [25], Colombia [26], India [27], Mexico [28], Lebanon [29], Brazil [30], and Spain [31].

Due to its nosocomial transmission and its ability to easily colonise the hospital environment, the SARS-CoV-2 pandemic has created an ideal atmosphere for $C$. auris dissemination. The hospital saturation, the equipment used, and the decreased efficacy of microbiology prevention systems are some of the main reasons for the increased C. auris spread during the actual SARS-CoV-2 pandemic, especially in developing countries [35].

\section{Hypotheses on the Origin of $C$. auris}

Since its first isolation in Japan almost a decade ago [6], one of the most enigmatic traits of $C$. auris has been the almost simultaneous and independent emergence of isolates of different clonality, as demonstrated by whole genome sequencing (WGS) studies [19]. Despite C. auris being detected retrospectively in several cases both from colonization and invasive samples, mainly in South Korea, the absence of this yeast in collections going back several decades was not due to identification problems [36]. After the first reports of cases of invasive infection in patients from Asia, Africa, and South America 
with strains belonging to phylogenetically different clades [19,37-40], C. auris began to be considered a pathogen of medical importance in humans. However, the mechanisms underlying the appearance of highly virulent and resistant strains in geographically distant regions without phylogenetic traceability since the first descriptions in the literature are still unknown.

The indiscriminate use of antifungal agents both in clinical practice and agro-industry has been proposed to contribute to the emergence of C. auris, and may partially explain its high degree of drug resistance [11]. Nevertheless, this hypothesis hardly justifies its appearance as a virulent human pathogen on three continents almost simultaneously [41], nor does its significant pathogenicity both in humans and in other animal experimental models [11,16,18-20,42,43].

Another suggested explanation for the emergence of $C$. auris and for its unusual characteristics has been the recent and progressive acquisition of virulence factors [42]. But, similarly, it is unlikely that these determinants of pathogenicity have been acquired nearly simultaneously in separated remote regions under different environmental and genetically distant isolates $[41,44]$.

Recently, global warming has been postulated as a feasible explanation for this unknown $[41,44,45]$. Of the large number of fungal species described in our planet, only a minority are human pathogens, mainly due to the high basal body temperature of mammals, which created a thermal restriction barrier, as well as the complex mechanisms of innate and adaptive immunity against fungal infection $[46,47]$.

Casadevall et al. compared thermal sensitivity of $C$. auris with other closely phylogenetically related Candida species, and demonstrated its relatively high thermotolerance [41]. Hence, it was hypothesised that $C$. auris could have overcome the thermal barrier of mammals, as a result of its adaptation to global warming and higher temperatures from an environmental reservoir, possibly in wetlands or coastal ecosystems. Later, it could have been transported by migratory animals such as birds to other areas of the planet where, after interspecific transmission in rural areas, human colonization and its subsequence appearance in healthcare facilities could take place. The recent environmental isolation of C. auris in tropical remote beaches of the Andaman Islands (India) [48] confirms for the first time the presence of an environmental niche and supports the global warming hypothesis in the emergence of $C$. auris.

\section{Microbiological Features of $C$. auris}

\subsection{Phylogeny}

C. auris is an ascomycete fungus within the clade Clavispora of the family Metschnikowiaceae and Saccharomycetales Order [49,50]. Although the evolutionary phylogenetic relationship of C. auris with other Candida species is not yet fully clarified due to the infrequency of some of the closest species, 5 clades have been described so far. These clades have been related to other species such as such as C. haemulonii, closely followed by C. pseudohaemulonii, and C. dobushaemulonii with $88 \%$ similarity [49,51], and recently, C. heveicola [6].

Due to the relative taxonomic proximity of these species, C. auris shares some of their phenotypic characteristics, preventing an adequate identification based on conventional biochemical methods [52].

Whilst clades I, III and IV are responsible for outbreaks of invasive infection by multidrug resistant strains, the clade II located geographically in east Asia has not been associated with nosocomial outbreaks. It presents a more benign antifungal drug susceptibility profile, a markedly different karyotype from the rest, and has been fundamentally described in ear infections, as it was at the time of its discovery $[6,53,54]$. Clade $V$, recently described in Iran [39], is highly infrequent, and owns a high degree of phylogenetic proximity with clades I, III and IV, although its sequence is relatively divergent from the rest [53]. Each of these clades presents isolates of the same clonality, restricted to a specific geographical area, but which historically emerged in a relatively simultaneous and independent manner [17], as previously discussed. 
Clade I has been described mainly in regions of the United Kingdom, India, and Pakistan. Clade II is found mostly in Japan and South Korea. Clade III is native to South Africa, and also includes samples from Spanish outbreaks, while clade IV constitutes that described in Venezuela. Finally, clade V has been described in Iran, with a single isolate from a patient who never left the country $[6,17,19,20,49,53-55]$.

\subsection{Culture, Growth, and Phenotypes}

C. auris is able to grow after $24 \mathrm{~h}$ of culture at $37^{\circ} \mathrm{C}$ on Sabouraud agar, where it develops opaque white to creamy colonies. Chromogenic media have recently become popular for C. auris culture and identification. In the medium CHROMagar Candida ${ }^{\circledR}$, colonies present with pink to pale purple tonalities. However, differences in the tone of the colonies have been reported, dependent on the country of origin and clade. Some authors have, hence, proposed these chromogenic media complemented with Pal agar (with extract of sunflower seeds) for presumptive identification of C. auris [56].

Although it is not able to grow in media with cycloheximide, C. auris presents a marked thermotolerance and salt tolerance, growing in a temperature range from $37-42{ }^{\circ} \mathrm{C}$, unlike other Candida or fungal species [15,20,41,43,49,57-60]. These particular traits, beyond modified chromogenic media, can also be used for its presumptive identification in microbiology laboratories with technical limitations or before definite molecular identification.

C. auris assimilates and weakly ferments glucose, saccharose, and trehalose; and assimilates raffinose, melezitose, soluble starch, and ribitol or adonitol. However, it is not capable of fermenting galactose, maltose, lactose, or raffinose [6]. This glycidic fermentation and assimilation profile also makes it possible to generate sensitive and specific culture media based on mannitol, dextrose, and dulcitol to isolate and presumptively identify C. auris in clinical practice [15].

Microscopically, C. auris is a yeast with $2-3 \times 2.5-5 \mu \mathrm{m}$ ovoid cells similar to C. glabrata [43] It presents two important clearly distinguishable phenotypes with different behaviour and virulence [43,61-69]:

- Non-aggregative phenotype: yeast cells arrange as isolated or, sometimes, coupled cells, similarly to other Candida species.

- Aggregative phenotype: some isolates keep daughter cells attached after budding, creating large aggregates that cannot be separated by physical disruption after vigorous vortexing for several minutes.

The different characteristics in behaviour, virulence, and pathogenicity determinants of both phenotypes will be posteriorly discussed.

Unlike other species of the genus Candida, such as C. albicans, considered the most virulent species of the group, and with high filamentation capacity [70-72], C. auris is not considered able to develop true hyphae, chlamydospores, or germ tubes $[34,36,58,73,74]$. The formation of very rudimentary pseudohyphae had only been described occasionally $[43,62]$. However, more recent studies have reported filamentation in some strains of C. auris under certain environmental conditions or stress $[61,71,75,76]$. Yue et al. described an in vivo inheritable phenotypic change or switch towards a filamentous or filamentationcompetent phenotype, induced by passage through the mammalian organism, different salt concentrations of $\mathrm{NaCl}$ between $10 \%$ and $26 \%$, and thermal changes [75]. Our group recently described filamentation in non-aggregative and aggregative strains in an invertebrate model in wax moth larvae at $37^{\circ} \mathrm{C}$ [61]. On the other hand, Bravo-Ruiz et al. were able to induce filamentation in vitro through genotoxic stimulation [76]. This possibility of pseudohyphae formation has finally been demonstrated in strains from the four main clades, according to the work of Fan et al. [77].

\subsection{Difficulties in C. auris Identification}

There are numerous methods used for the identification of Candida species in clinical microbiology laboratories. Nevertheless, most of them use commercial systems of biochemical characterization, which are unable to properly identify C. auris. These methods usually 
misidentify it as C. haemulonii, Rhodotorula glutinis, Saccharomyces cerevisiae, or, less frequently, as other Candida species such as C. famata, C. dobushaemulonii, C. sake, C. lusitaniae, C. albicans, C. guilliermondii, or C. parapsilosis [17,18,43,52,57,58,73,78-83]. However, erroneous identification has been reported with more complex diagnostic methods, such as filmarray systems [84] and matrix-assisted laser desorption/ionisation time-of-flight (MALDI-TOF) [85]. The main misidentified species of different commercial biochemical systems is represented in Figure 1.

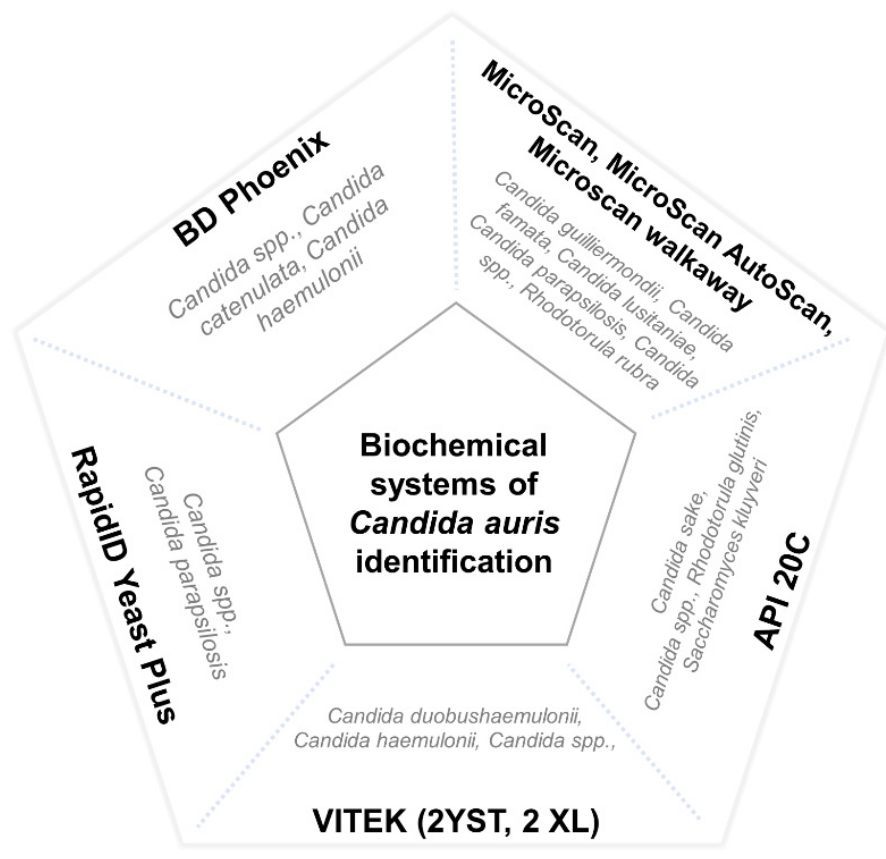

Figure 1. Main misidentified species of different commercial biochemical systems. Misidentification of $C$. auris by means of the VITEK systems has specially been reported with isolates of the east Asian and African clades.

In primary or secondary hospitals with fewer resources, as well as in developing countries with limited access to sophisticated and expensive methods such as MALDI-TOF or molecular techniques, such identification sometimes arrives at Candida spp. without reaching the species level in non-invasive samples [19,86]. However, due to its relevance for public health, accurate and rapid diagnostic methods are needed to facilitate prompt diagnosis, effective patient management, and control of nosocomial outbreaks.

At present, the new MALDI-TOF systems, after including the specific spectra in the databases [87-89], are able to provide specific diagnoses at species level. In developing countries with limited access, this method could be replaced by DNA detection techniques such as PCR [89]. Despite the sequencing of genetic loci (RPB1, RPB2, D1/D2) and the internal transcribed spacer (ITS) of ribosomal RNA (rRNA) being commonly used, especially in reference centres [58,74,90], different PCR endpoint trials, multiplex PCR [91], or PCR of Restriction Fragment Length Polymorphisms (RFLP) [89,92] could be more accessible in centres with economic or equipment limitations. Recently, two commercially available PCR assays, AurisID (OLM, Newcastle Upon Tyne, UK) and Fungiplex Candida Auris RUO Real-Time PCR (Bruker, Bremen, Germany) have been shown to reliably identify C. auris, even at low DNA concentrations [93].

In addition, many microbiology laboratories presumptively identify C. auris using chromogenic media, due to better accessibility and lower cost. Consequently, some media which allow for rapid screening after $24 \mathrm{~h}$ of incubation have been created, such as HiCrome C. auris [94]. Furthermore, the culture medium CHROMagar Candida, complemented with Pal agar [56], has been shown to be useful in the differentiation of C. auris from 
C. haemulonii. Due to its triazole resistance, the use of high concentration fluconazole as media supplementation could optimise the presumptive recognition of $C$. auris in higher prevalence zones which lack easy access to definitive identification techniques [95].

\subsection{Virulence}

Since $C$. auris became a major public health problem, efforts have been devoted to investigating the pathogenicity degree of several clones, strains, and worldwide isolates of C. auris. Nevertheless, data on its virulence compared to other Candida species, as well as on its phenotypical, morphological, or molecular pathogenicity determinants, are still limited.

C. albicans is considered the most virulent species of the Candida genus $[70,71,96]$. Candida species express several pathogenicity factors that contribute to their pathogenicity and virulence within the host. Among them, it is important to highlight the synthesis of molecules such as phospholipases, aspartic-proteases, or molecules related to the recognition of host proteins that increase tissue adhesins, and morphogenesis, as well as a phenotypic switch to a filamentous phenotype, enabling higher adaptability to intrahost changes [96].

Despite C. auris initially being considered unable to filament in vivo or, in any case, only able to produce rudimentary pseudohyphae under stress $[75,76]$, some works using strains from different origins and clones have described an in vivo virulence similar or even greater than that of C. albicans $[43,62,97]$. Nonetheless, the results of the few studies on the pathogenicity of $C$. auris are relatively diverse, as seen in Table $1[43,61-65,97]$. Differences have been noted, not only in comparison with other species of the genus, but also regarding different clones, strains, and individual isolates. Further studies are, hence, needed, using a larger number of strains from different geographical regions, clinical isolates, and clades $[50,61,65,98]$.

Table 1. Virulence of C. auris in different experimental animal models.

\begin{tabular}{ccc}
\hline Organism & Virulence Results & Reference \\
\hline C. elegans & C. hameulonii $<$ C. auris $=$ C. albicans & {$[99]$} \\
C. elegans & Non-Ag C. auris $>$ Ag-C. auris & {$[67]$} \\
D. rerio & C. auris $>$ C. albicans $>$ C. haemulonii & {$[97]$} \\
D. melanogaster & C. auris $>$ C. albicans & {$[100]$} \\
& Non-Ag C. auris $=$ Ag C. auris $>$ C. albicans & \\
G. mellonella & C. albicans $>$ C. auris $>$ C. parapsilosis \\
Non-Ag C. auris $>$ Ag-C. auris & {$[61]$} \\
G. mellonella & Non-invasive isolates $=$ invasive isolates & \\
G. mellonella & C. auris $\geq$ C. albicans & {$[43]$} \\
Non-Ag C. auris $>$ Ag-C. auris & {$[62]$} \\
G. mellonella & Non-Ag C. auris $\geq$ C. albicans and C. glabrata & {$[66]$} \\
G. mellonella & Ag-C. auris $=$ C. glabrata & {$[63]$} \\
G. mellonella & C. auris $<$ C. albicans & {$[64]$} \\
G. mellonella & Non-ag C. auris $=$ Ag C. auris & C. auris $<$ C. albicans \\
Neutropenic Mus musculus & Non-ag C. auris $=$ Ag C. auris & {$[67]$} \\
\hline
\end{tabular}

Non-ag: non aggregative; Ag: aggregative.

During the last several years, several research groups have analysed the pathogenicity differences of $C$. auris in comparison to other Candida species. Different models have been used: from in vitro studies assessing different transcriptional profiles from strains with different phenotypes [101], to animal models with a diverse complexity. These include invertebrate models in Caenorrhabditis elegans [67,99], Drosophila melanogaster [100], and the recently popularised model in wax moth larvae, Galleria mellonella [43,61-67], as well as 
vertebrates such as the traditional murine model [64], and, more recently, the zebrafish Danio rerio [97].

G. mellonela has recently gained importance in the study of fungal pathogenesis and, especially, Candida spp. virulence. Owing to the functional and structural similarity of the larval innate immune system to that of mammals, its low cost, as well as the possibility of working with larger samples in short timeframes thanks to its short vital cycle and, importantly, due to the lack of ethical implications involved, its popularity has been increasing recently [61,71,102-107].

The first data of experimental pathogenicity of $C$. auris came from the studies of Borman et al. [43], using 12 isolates from the United Kingdom outbreak. They showed more aggregative phenotypes of $C$. auris to be in vivo than non-aggregative strains. Moreover, the first were considered almost as virulent as C. albicans, despite their striking inability to filament. In addition, Sherry et al. [62], who also used four different strains from the United Kingdom, documented that non-aggregative phenotypes of $C$. auris showed a higher lethality than C. albicans reference strain SC5314, using a standardised inoculum of $10^{5}$ colony forming units (CFU), while $C$. glabrata and aggregative $C$. auris were significatively less virulent. In a model of C. elegans using 37 C. auris strains from Venezuela [9], they also appeared to show a similar pathogenicity degree to C. albicans, but less virulence than C. haemulonii [99]. However, these results could not be reproduced using strains of other geographical origins.

The works of Carvajal et al. [66] and Muñoz et al. [64] analysed the differential pathogenicity using Colombian strains. The study of the first group in G. mellonella did not show significative differences in the virulence of aggregative and non-aggregative strains, with more than $50 \%$ of the strains being less lethal than the reference strain of C. albicans SC5314; these findings are similar to the results obtained by Romera et al. [63] with Spanish isolates, also in G. mellonella. The second group developed both a G. mellonella and a neutropenic murine model, and used C. albicans SC5314 and ATCC10231 strains as a high pathogenicity control, and C. haemulonii as a low virulence control. Despite C. auris phenotypes not being determined, the four strains used showed a significant intermediate lethality between C. albicans and C. haemoulonii in G. mellonella, as reported by Garcia-Bustos et al. [61], but these results were not replicated in the murine model.

Therefore, this heterogenicity in intra- and interspecific virulence advocates for the hypothesis that the morphogenetic variability is an inherent trait of $C$. auris, and an indicator of its flexibility and adaptability to different environments and stimuli [61], particularly after some authors induced aggregation after exposition to triazoles and echinocandins [108].

This potential ability to phenotypically switch may result from a survival mechanism outside of the host. In fact, isolates from environmental and epidemiological surveillance samples more frequently presented an aggregative phenotype. Moreover, they demonstrated a greater ability to form biofilm structures; both traits related to the difficulty for their definitive eradication in the health environment and in colonised patients [109,110]. In addition, replicative aging resulting from asymmetric cell division has been shown to cause further phenotypic differences, and older $C$. auris cells have been associated with increased virulence in G. mellonella [111].

The pathogenicity determinants of $C$. auris are not completely clarified. The formation of biofilms and filamentation constitute two of the main virulence factors of Candida species. Other important factors have been described, such as phenotypic switch, metabolic flexibility and adaptation to different $\mathrm{pH}$, production of extracellular hydrolytic and cytolytic toxins, heat shock proteins (HSP), and development of adherence and recognition mechanisms of surfaces and host cells [112,113].

As previously stated, C. auris is able to filament both in vivo and in vitro [61,75-77]. However, the pathogenic implication of hyphae or pseudohyphae formation in C. auris is still unknown. Some studies have not been able to demonstrate the expression of proteins related to the formation of these structures, such as the candidalysin (ECE1) or hyphal cell wall protein (HWP1) in certain C. auris strains [49]. Yue et al. [75] analysed the expression 
profile of genes related to the regulation of filamentation, and discovered similarities with C. albicans, showing an increased expression of genes implicated in hyphae formation such as HGC1, ALS4, COH1, FLO8, PGA31, and PGA45 in filamentous strains, with regard to strains that only showed yeast-form structures.

C. auris is able to form biofilms, a trait which also constitutes a major challenge in clinical practice. The colonization of surfaces in patients undergoing any type of instrumentalisation increases, on the one hand, the risk of invasive candidiasis and generating new outbreaks, and decreases, on the other hand, the possibility of eradicating patient colonisation. A large number of IFI cases due to $C$. auris have been described related to health devices, such as urinary tract infections (UTI) in patients with indwelling catheters, cardiovascular infections, or neurosurgical instrument-related infections [16-18,114,115]. The $C$. auris tendency to form biofilms in human skin as well as in animal skin models with an elevated microbiological burden [116] has been related to an increased expression of adhesins (IFF4, CSA1, PGA26, PGA52, PGA7, HYR3, and ALS5) [117], with differential regulation based on the biofilm maturity $[117,118]$. In addition, biofilms also influence drug resistance by physical means, by hindering drug penetration in the most isolated regions of the dense biofilms $[117,119]$, and expressing genes related to biofilm with added efflux pump action or glucan modifier enzyme action [117,119,120].

Some genomic studies have demonstrated that $C$. auris shares some of the pathogenicity determinants with other species of Candida, such as secretion of aspartic-proteases (SAP), lipases, phospholipases, and YPS proteases $[67,69]$. Other virulence factors include the expression of oxidoreductases, transferases, hydrolases [67], and haemolysins [121].

Finally, immune evasion has recently been considered an important trait of C. auris. Beyond phenotypic plasticity, some works have reported the ability of this fungus to evade neutrophil attack and effective phagocytosis both in human and animal models [116,122]. This finding is in line with previous clinical works, suggesting that neutropenia is not an important risk factor for invasive candidiasis by C. auris [61].

\subsection{Antifungal Resistance}

An important proportion of $C$. auris strains are resistant to multiple, and in some cases, all available antifungal treatments used in clinical practice. The estimated frequency of resistance to fluconazole, amphotericin B, and echinocandins surpasses $90 \%, 30 \%$, and around $5 \%$, respectively, according to CDC tentative breakpoints [10,123]. As a consequence, the management of IFI caused by $C$. auris is extremely complicated.

As with other microbiological characteristics of the species, the degree of drug resistance is highly variable between strains $[10,123,124]$. Different isolates also show variable susceptibility profiles to triazoles, even within the same clade $[10,125,126]$, evidencing high regional, intra-, and inter-clade diversity.

Ergosterol is the main component of the fungal cell wall, and is synthesised by lanosterol demethylase enzyme, coded by the ERG11 gene. Ergosterol is the target of polyenes such as amphotericin B, and the enzyme 14-alpha demethylase is the target azole drugs $[10,127]$. Several mutations have been detected in this gene, which partially explains the resistance to triazole drugs of C. auris (F126L, Y132F, VF125AL, and K143R) $[19,126]$. These mutations frequently coexist with others in resistance-related genes, such as MDR1, CDR1, YMC1, and TAC1B [128-130]. Less frequently, mutations in the FKS1 gene (S639F and F635Y) and in the chitin synthase gene CHS1 have been documented [131]. FKS1 codes the catalytic subunit of the synthase of 1,3-beta-D-glucane-the target of echinocandins-which bestows its resistance [124]. Moreover, mutations in the gene CHS1 were also found to cause echinocandin resistance [131].

Flucytosine is a nucleoside analogue that inhibits fungal nucleic acid synthesis, and has been frequently used in combination regimes to treat severe invasive infections by C. auris, especially those associated with external devices. The pro-drug is activated by fungal uracil-phosphoribosyltransferase, encoded by the FUR1 gene [132]. Unlike with 
other Candida species, an F311I substitution in the FUR1 gene has been reported in a flucytosine-resistant $C$. auris strain [123].

Furthermore, beyond molecular mechanisms of antifungal resistance in C. auris, phenotypic modifications and biofilm formation also influence the degree of drug resistance $[61,108,110]$. As previously stated, replicative aging resulting in asymmetric cell division and phenotypically distinct daughter cells has been associated with increased virulence, but also drug resistance $[111,133]$. Senescent $C$. auris cells showed a higher tolerance to fluconazole, micafungin, flucytosine, and amphotericin B. Bhattacharya et al. [111] demonstrated that fluconazole resistance in these cells was due to gene duplication in CDR1 and ERG11. Both high- and low-density C. auris biofilms are associated with high levels of resistance to azoles, amphotericin B, and micafungin [13]. Biofilms confer pharmacodynamic resistance to antifungal agents related to low penetration in infected tissue after parenteral administration, but they can also overexpress ATP-binding cassette (ABC) and major facilitator superfamily (MFS) transporters. The resistance to triazoles has been shown to be increased by 4-16-fold in these cases [117]. The presence of glucan and mannan polysaccharides able to sequestrate antifungal drugs, the protection of cells from oxidative stress by the extracellular matrix, and phenotypic plasticity culminate in a rise in the drug resistance in this yeast to voriconazole by 4 -fold, amphotericin B by 20 -fold, and to micafungin by 60 -fold [13].

To date, the highest rates of multidrug resistance have been described for clade I isolates, in regions from United Kingdom, India, and Pakistan. Resistance to azoles in strains from clade I rises up to $97 \%$, and more than $50 \%$ of isolates show resistance to amphotericin B, or present resistance to two or more antifungal agents [38]. Strains from Venezuela belonging to clade IV also exhibit amphotericin B resistance rates of approximately $50 \%$, together with the highest rate of resistance to echinocandins, such as micafungin, of around 7\% [38]. This rate is similar to that observed in Spanish isolates from clade III [17,134]. Contrarily, strains from clade II show fluconazole resistance from $11-14 \%[13,119]$.

\subsection{Persistence in the Healthcare Environment}

C. auris shedding between patients is widely facilitated by its capability of persisting in viable forms in the environment for long periods of time [135]. Viable yeasts have been recovered from surfaces in rooms and bathrooms of the healthcare environment, such as mattresses, pillows, bed sheets, tables, sinks, toilet, walls, door and tap handles, as well as sanitary material such as temperature probes, blood pressure cuffs, mechanical ventilators and tubes, oxygen masks, and personal devices such as mobile phones [18,20,135-138].

Furthermore, it is able to survive on non-porous abiotic surfaces, such as plastic or steel, for up to 28 days [15,59].

\section{Clinical Manifestations}

\subsection{Colonization}

C. auris possess a unique capacity to be transmitted from patient to patient through contact. Contrary to other Candida species, this species is not naturally present in the human organism as saprophytic flora, and is not a common commensal in the gastrointestinal tract as can happen with other species such as C. albicans [139-141].

Despite its greater thermotolerance [41], C. auris is able to colonise multiple anatomical surfaces, showing special predilection for the skin, and being frequently found not only in the axilla or groin, but also in oropharyngeal or anorectal exudates. In addition, it is commonly isolated in urine, nasal fossa, and external auditory conduct, and it easily colonises wounds [17]. However, the tissue with the greatest permittivity to multiplication and transmission among hosts seems to be the skin [40]. After colonising the patient's skin, C. auris yeasts produce a complex biofilm of multiple layers with high adherence and fungal burden, proliferating in regions which reproduce the humid conditions of sweat 
in folds and covered surfaces [116]. This happens to a greater extent than in other more commonly isolated species, such as C. albicans.

The presence of instrumentation and external devices in which C. auris can form biofilms increases the risk of multifocal colonisation, the persistence of this colonisation, and dramatically decreases the possibilities of its eradication.

The colonisation of patients in healthcare environments occurs rapidly, within hours after exposure, and can last for weeks, months, or even years [40,142], despite the use of agents such as chlorhexidine, nystatin, and echinocandins [20,143]. In fact, this persistent colonisation can lead to repeated IFI episodes over several months, regardless of an optimal antifungal therapy [142,144].

Additionally, Biswal et al. [20] reported hand colonisation in 3\% of screened healthcare personnel. Therefore, proper handwashing protocols must be implemented in the clinical setting, as the colonisation of workers might be an important vehicle for $C$. auris transmission.

\subsection{Infection}

Since its first description in 2009 , C. auris has been isolated in multiple invasive locations. The clinical manifestation and the organic spectrum of IFI caused by C. auris do not particularly differ from other Candida species. As such, the candidaemia or bloodstream infection is the most common manifestation [135,145]. Many other infections associated with intravascular devices have also been described, such as central catheters, endocarditis $[17,74,115,146]$, urinary tract infections or candiduria [142,144], central nervous system infections [147], respiratory tract infections [15,49,62,74], intra-abdominal infections $[17,148]$, skin and soft tissue infections [55,58], external otitis [6,134], otomastoiditis [44], panophthalmitis [149], and even osteomyelitis and spondylodiscitis [83,150] (Figure 2). In fact, in our institution (University and Polytechnic Hospital La Fe, Valencia, Spain), C. auris colonisation was considered a temporary absolute contraindication for cardiac transplantation, due to high rates of cardiovascular infection and death.

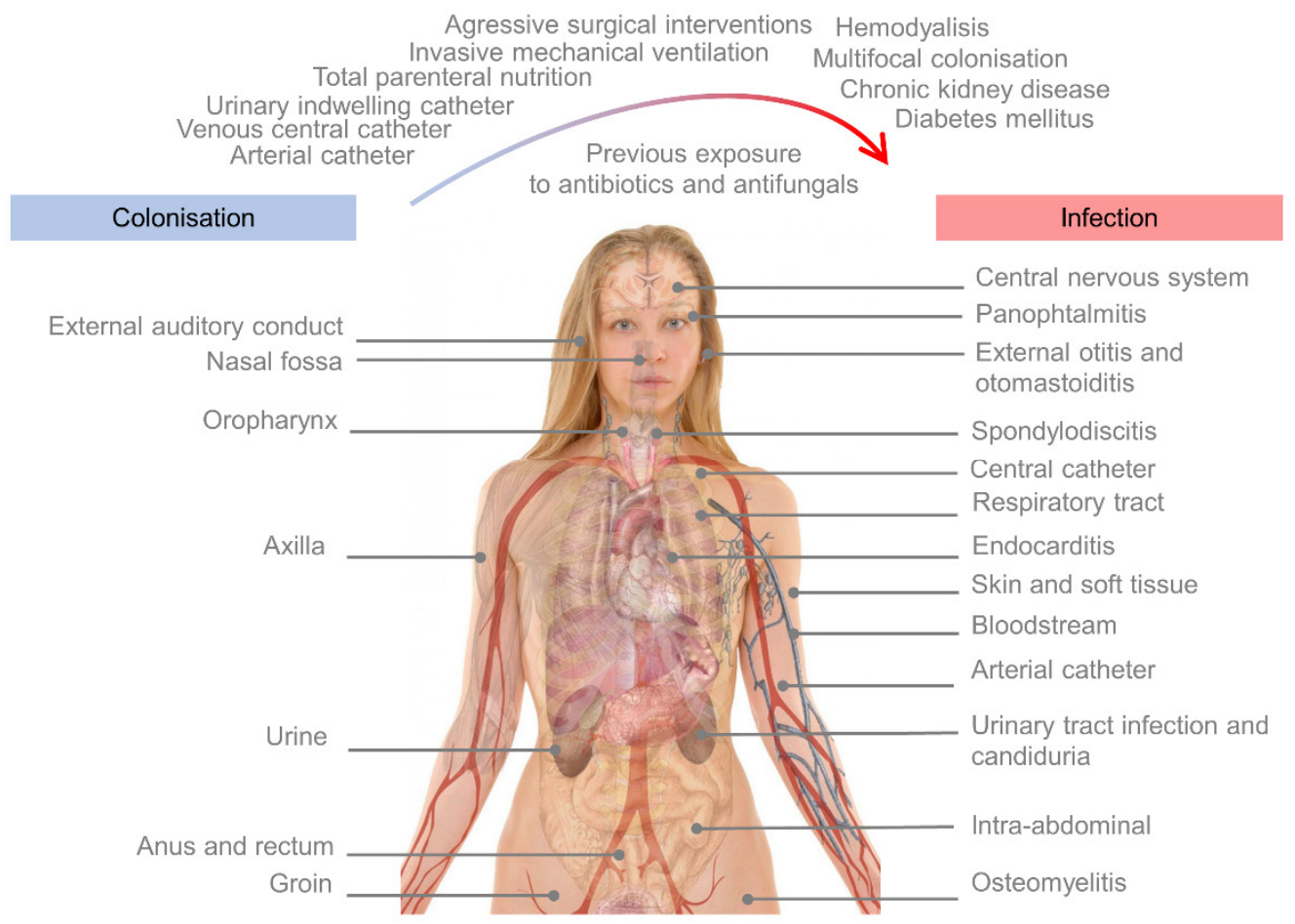

Figure 2. Schema representing the most common colonisation, invasive infection sites, and risk factors for deep-seated infections in patients colonised by C. auris. 


\subsection{Risk Factors of Invasive Fungal Infection in C. auris Colonised Patients}

Due to the high colonising power of $C$. auris, the scientific community has overturned studying the risk factors for the development of candidaemia or IFI, especially in colonised patients of critical care units. Early identification of risk factors may help to estimate the risk of candidaemia, and identify a high-risk population that could benefit from early or prophylactic antifungal treatment, as well as control of modifiable risk factors.

The risk factors do not greatly differ from those of other Candida species, and include the presence of not only central venous catheters, arterial catheters, indwelling catheters, but also conditions such as chronic kidney disease, total parenteral nutrition (TPN), diabetes mellitus (DM), haemodialysis, invasive mechanical ventilation, aggressive surgical interventions, sepsis, multifocal colonisation, and previous exposure to antifungals or antibiotics $[16,18,20,151-153]$. In a previous study undertaken by our group, we developed and validated a predictive model of candidaemia in critically ill colonised patients through a prospective approach, creating an equation that could help to predict the estimated risk of candidaemia, dependent on the present risk factors [151]. TPN (adjusted OR 3.73), previous surgery (adjusted OR 1.03), sepsis (adjusted OR 1.75), previous exposure to antifungal agents (adjusted OR 1.17), arterial catheters (adjusted OR 1.46), central venous catheters (adjusted OR 1.21), presence of advanced chronic kidney disease (adjusted OR 1.35), and multifocal colonization (adjusted OR of unifocal colonisation 0.46) were proven to be independent predictors of candidaemia.

The most common colonisation sites, invasive infection sites, and risk factors are graphically represented in Figure 2.

\subsection{Complications, Mortality, and Prognosis}

Candidaemia is the most frequent severe manifestation, and its complications depend on a constellation of several diverse and related factors. Some of these factors include pathogen traits, such as resistance pattern or strain virulence, factors dependent on the infection itself, such as its origin or its extension, and host factors, such as comorbidity and therapeutic limitations due to pharmacodynamic or pharmacokinetic parameters, and drug availability.

Patients with candidaemia can develop fungal blood dissemination to different organs, producing a generalised infection, septic metastasis, septic shock, multiorgan failure and, finally, death on many occasions, despite optimal antifungal therapy. Moreover, colonisation and localised infections can lead to the appearance, perpetuation, or relapse of candidaemia months after adequate treatment $[16,18,20,40,142,144]$.

The mortality of invasive infections caused by $C$. auris is comparatively larger than the majority of Candida species, and varies from $30 \%$ to more than $70 \%$, according to the available series $[7,13,16,18-20,134,147]$. Early detection and prompt treatment are associated with greater survival.

\section{Treatment of Invasive $C$. auris Infections}

The greater problem in the management of $C$. auris-infected patients is the multi-, and on some occasions, pandrug resistance of the isolates, which confer a high therapeutic failure rate with all types of antifungal treatments [154].

According to the CDC recommendations [155], and to the limited available data in absence of clinical guidelines, echinocandins are the initial recommended treatment for C. auris infections. Despite the fact that many of the isolates are susceptible to this therapeutic group, resistance is easily acquired, and the incidence of strains with decreased susceptibility is increasing rapidly [134]. Patient monitoring must be close, and if there is no clinical or microbiologic response within five days of the initial treatment, echinocandins should be changed for amphotericin B, or amphotericin B should be added in a combination regime [155]. The therapeutic measures must be accompanied by a judicious management of antimicrobials, medical devices, and instruments, as well as an adequate control of the infectious foci. 
There is growing evidence of the efficacy and effectivity of combination regimes, using echinocandins with a second or even third drug, such as amphotericin B, flucytosine, voriconazole, or isavuconazole, among others $[156,157]$. Less frequently, combinations with other drugs such as co-trimoxazole [158], lopinavir [159], aprepitant [160], or suloctidil [161] have been used. However, many of these results have been obtained in vitro, and need to be further validated in vivo.

Nevertheless, multidrug resistance in C. auris has urged research for new molecules with antifungal activity, as society will face a foreseeable scenario of more complex infections with a higher rate of therapeutic failure. Some of these new compounds are detailed in Table 2.

Table 2. Novel drugs, molecules, or compounds with proven activity against $C$. auris.

\begin{tabular}{cc}
\hline Antifungal Agents & Reference \\
\hline Fosmanogepix (APX001A) & {$[162]$} \\
Arylamidine (T-2307) & {$[163]$} \\
Ibrexafungerp (SCY-078) & {$[164]$} \\
Nitroxoline & {$[165]$} \\
PC945 & {$[157]$} \\
VT-1598 & {$[166]$} \\
Other compounds & \\
\hline Carvacrol & {$[167]$} \\
Crotamine & {$[168]$} \\
Ebselen & {$[161]$} \\
Farnesol & {$[169]$} \\
Histatin 5 & {$[170]$} \\
Rocaglates & {$[171]$} \\
\hline
\end{tabular}

\section{Prevention and Control of $C$. auris}

All of the factors previously described show that $C$. auris combines all of the essential characteristics for a pathogen to pose a threat to public health:

- Potential to spread through horizontal transmission and to cause outbreaks;

- Ability to cause serious and life-threatening infections;

- Multi-resistance profile and limitations for optimal treatment.

Currently, and as defined by the CDC in its report on antibiotic resistance threats in the United States of 2019, C. auris is considered a public health threat that requires urgent and aggressive action, together with carbapenem-resistant Acinetobacter, and carbapenemresistant Enterobacteriaceae, among others. Therefore, the measures for control and prevention are similar, and based on previous protocols.

All potential sources and reservoirs should be detected, and Candida identification should be performed at a species level, even from non-sterile sites [42,135]. Clinicians should also be directly alerted after $C$. auris isolation, and further retrospective case-finding studies should be ideally performed, in order to improve the traceability of cases.

The patient must be immediately isolated and identified, and all health assistance must be performed following transmission-based precautions and use of personal protective equipment, with special precautions when appropriate. Negative pressure rooms have been proposed when available for C. auris colonised patients [135]. We recommend the periodic reassessment of colonisation on a weekly basis, through the performance of epidemiological surveillance cultures from the axilla, groin, oropharyngeal exudate, and anal and rectal samples. Invasive samples should be taken in an individualised manner, especially in patients undergoing surgical interventions, or any kind of instrumentation.

Patients, and healthcare personnel in close contact with them, should be screened for C. auris, and appropriate hand hygiene programs should be implemented for all healthcare personnel in potential contact with $C$. auris-colonised patients. 
Environmental cleaning should be performed regularly, preferably preferably sodium hypochlorite or hospital grade sporicidal disinfectants, at a minimum of 4-5 times a week. Single-patient devices and patient-use items should be utilised when feasible, and all shared medical equipment should be thoroughly disinfected according to the manufacturer instructions [135]. In an outbreak setting, environmental cultures should be performed weekly.

In patients with known risk factors for candidaemia, skin and mucosal decontamination with chlorhexidine should be considered, and all manipulations must be performed following adequate care bundles and protocols.

Programs for the optimisation of antibiotic and antifungal stewardship are encouraged to be implemented in all facilities with C. auris isolations.

\section{Conclusions}

C. auris has unprecedently emerged as a multidrug resistant pathogen, with an alarming increase in the incidence of nosocomial outbreaks with staggering mortality and transmission rates, that has put health authorities and institutions worldwide in check for more than a decade now. Astonishingly, its emergence has been independent and simultaneous in several continents. Despite the fact that the scientific community has devoted efforts to exploring its biological traits, there is little evidence on its pathogenicity and the complex host-pathogen interactions. Due to its unique features not observed in other yeasts, it has been categorised as an urgent threat by the Centers for Disease Control and Prevention and other international agencies concerned with disease control. Furthermore, the current SARS-CoV-2 pandemic has created the ideal conditions for its spread, allowing it to become a lurking threat for COVID-19 patients, and several outbreaks of C. auris invasive infections have been reported in COVID-19 wards. Progress in its identification has been optimal, but much remains to be done to guarantee equity in lower-income countries, which often have limitations for the use of definite diagnostic molecular or spectrometry tools. Contrarily, the treatment of severe and complex invasive infections still takes a shot in the dark, and further strategies need to be assessed with novel drugs and combination regimes for enhancing outcomes. Improving control measures, early diagnosis, knowledge of risk factors for invasive infection, antifungal stewardship, and education of healthcare providers is needed to contain the threat of $C$. auris, a timely reminder that pathogenic fungi deserve equal attention in the new era of emerging infectious diseases.

Author Contributions: Conceptualization, V.G.-B., M.D.C.-N., A.R.-S., A.C.R.-G., J.P.; Literature search, V.G.-B., M.D.C.-N., A.R.-S., A.C.R.-G., M.S., M.Á.T., J.P.; Writing—original draft preparation, V.G.-B., M.D.C.-N.; Writing-review and editing, V.G.-B., M.D.C.-N., A.R.-S., A.C.R.-G., M.S., M.Á.T., J.P.; Elaboration of Tables and Figures, V.G.-B., M.D.C.-N., A.C.R.-G.; Supervision, A.R.-S., M.S., M.Á.T., J.P. All authors have read and agreed to the published version of the manuscript.

Funding: This study has been funded by the Instituto de Salud Carlos III with registry code PI17/01538.

Institutional Review Board Statement: Not applicable.

Informed Consent Statement: Not applicable.

Conflicts of Interest: Authors report no conflict of interest in relation to the present work.

\section{References}

1. Corsi-Vasquez, G.; Ostrosky-Zeichner, L. Candida auris: What have we learned so far? Curr. Opin. Infect. Dis. 2019, 32, 559-564. [CrossRef]

2. Pfaller, M.A.; Diekema, D. Epidemiology of Invasive Candidiasis: A Persistent Public Health Problem. Clin. Microbiol. Rev. 2007, 20, 133-163. [CrossRef]

3. Lamoth, F.; Lockhart, S.R.; Berkow, E.L.; Calandra, T. Changes in the epidemiological landscape of invasive candidiasis. J. Antimicrob. Chemother. 2018, 73, i4-i13. [CrossRef] [PubMed]

4. Mathur, P.; Hasan, F.; Singh, P.K.; Malhotra, R.; Walia, K.; Chowdhary, A. Five-year profile of candidaemia at an Indian trauma centre: High rates of Candida auris blood stream infections. Mycoses 2018, 61, 674-680. [CrossRef] [PubMed] 
5. Adam, R.D.; Revathi, G.; Okinda, N.; Fontaine, M.; Shah, J.; Kagotho, E.; Castanheira, M.; Pfaller, M.; Maina, D. Analysis of Candida auris fungemia at a single facility in Kenya. Int. J. Infect. Dis. 2019, 85, 182-187. [CrossRef] [PubMed]

6. Satoh, K.; Makimura, K.; Hasumi, Y.; Nishiyama, Y.; Uchida, K.; Yamaguchi, H. Candida auris sp. nov., a novel ascomycetous yeast isolated from the external ear canal of an inpatient in a Japanese hospital. Microbiol. Immunol. 2009, 53, 41-44, Erratum in Microbiol. Immunol. 2018, 62, 205. [CrossRef]

7. Rudramurthy, S.; Chakrabarti, A.; Paul, R.A.; Sood, P.; Kaur, H.; Capoor, M.R.; Kindo, A.J.; Marak, R.S.K.; Arora, A.; Sardana, R.; et al. Candida auris candidaemia in Indian ICUs: Analysis of risk factors. J. Antimicrob. Chemother. 2017, 72, 1794-1801. [CrossRef] [PubMed]

8. Magobo, R.; Corcoran, C.; Seetharam, S.; Govender, N.; Naicker, S. Candida auris: An emerging, azole-resistant pathogen causing candidemia in South Africa. Int. J. Infect. Dis. 2014, 21, 215. [CrossRef]

9. Calvo, B.; Melo, A.S.; Perozo-Mena, A.; Hernandez, M.; Francisco, E.C.; Hagen, F.; Meis, J.F.; Colombo, A.L. First report of Candida auris in America: Clinical and microbiological aspects of 18 episodes of candidemia. J. Infect. 2016, 73, 369-374. [CrossRef]

10. Du, H.; Bing, J.; Hu, T.; Ennis, C.L.; Nobile, C.J.; Huang, G. Candida auris: Epidemiology, biology, antifungal resistance, and virulence. PLoS Pathog. 2020, 16, e1008921. [CrossRef]

11. Chowdhary, A.; Sharma, C.; Meis, J.F. Candida auris: A rapidly emerging cause of hospital-acquired multidrug-resistant fungal infections globally. PLoS Pathog. 2017, 13, e1006290. [CrossRef]

12. Ku, T.S.N.; Walraven, C.J.; Lee, S.A. Candida auris: Disinfectants and Implications for Infection Control. Front. Microbiol. 2018, 9, 726. [CrossRef] [PubMed]

13. Chakrabarti, A.; Sood, P. On the emergence, spread and resistance of Candida auris: Host, pathogen and environmental tipping points. J. Med. Microbiol. 2021, 70, 1318. [CrossRef] [PubMed]

14. Iguchi, S.; Itakura, Y.; Yoshida, A.; Kamada, K.; Mizushima, R.; Arai, Y.; Uzawa, Y.; Kikuchi, K. Candida auris: A pathogen difficult to identify, treat, and eradicate and its characteristics in Japanese strains. J. Infect. Chemother. 2019, 25, 743-749. [CrossRef] [PubMed]

15. Welsh, R.M.; Bentz, M.L.; Shams, A.; Houston, H.; Lyons, A.; Rose, L.J.; Litvintseva, A.P. Survival, Persistence, and Isolation of the Emerging Multidrug-Resistant Pathogenic Yeast Candida auris on a Plastic Health Care Surface. J. Clin. Microbiol. 2017, 55, 2996-3005. [CrossRef] [PubMed]

16. Eyre, D.W.; Sheppard, A.; Madder, H.; Moir, I.; Moroney, R.; Quan, T.P.; Griffiths, D.; George, S.; Butcher, L.; Morgan, M.; et al. A Candida auris Outbreak and Its Control in an Intensive Care Setting. N. Engl. J. Med. 2018, 379, 1322-1331. [CrossRef] [PubMed]

17. Ruiz-Gaitán, A.; Moret, A.M.; Tasias-Pitarch, M.; Aleixandre-López, A.I.; Morel, H.M.; Calabuig, E.; Salavert-Lletí, M.; Ramírez, P.; López-Hontangas, J.L.; Hagen, F.; et al. An outbreak due to Candida auris with prolonged colonisation and candidaemia in a tertiary care European hospital. Mycoses 2018, 61, 498-505. [CrossRef]

18. Ruiz-Gaitán, A.; Martínez, H.; Moret, A.M.; Calabuig, E.; Tasias, M.; Alastruey-Izquierdo, A.; Zaragoza, O.; Mollar, J.; Frasquet, J.; Salavert-Lletí, M.; et al. Detection and treatment of Candida auris in an outbreak situation: Risk factors for developing colonization and candidemia by this new species in critically ill patients. Expert Rev. Anti-Infect. Ther. 2019, 17, 295-305. [CrossRef]

19. Lockhart, S.R.; Berkow, E.L.; Chow, N.; Welsh, R.M. Candida auris for the Clinical Microbiology Laboratory: Not Your Grandfather's Candida Species. Clin. Microbiol. Newsl. 2017, 39, 99-103. [CrossRef]

20. Schelenz, S.; Hagen, F.; Rhodes, J.L.; Abdolrasouli, A.; Chowdhary, A.; Hall, A.; Ryan, L.; Shackleton, J.; Trimlett, R.; Meis, J.F.; et al. First hospital outbreak of the globally emerging Candida auris in a European hospital. Antimicrob. Resist. Infect. Control. 2016, 5,1-7. [CrossRef]

21. Centers for Disease Control and Prevention (CDC). Antibiotic Resistance Threats in the United States. Centers for Disease Control. December 2019. Available online: https:/ / www.cdc.gov/drugresistance/pdf/threats-report/2019-ar-threats-report-508.pdf (accessed on 14 October 2021).

22. Kadri, S.S. Key Takeaways From the U.S. CDC's 2019 Antibiotic Resistance Threats Report for Frontline Providers. Crit. Care Med. 2020, 48, 934-945. [CrossRef] [PubMed]

23. Prestel, C.; Anderson, E.; Forsberg, K.; Lyman, M.; De Perio, M.A.; Kuhar, D.; Edwards, K.; Rivera, M.; Shugart, A.; Walters, M.; et al. Candida auris Outbreak in a COVID-19 Specialty Care Unit-Florida, July-August 2020. Morb. Mortal. Weekly Rep. 2021, 70, 56-57. [CrossRef] [PubMed]

24. Hanson, B.M.; Dinh, A.Q.; Tran, T.T.; Arenas, S.; Pronty, D.; Gershengorn, H.B.; Ferreira, T.; Arias, C.A.; Shukla, B.S. Candida auris Invasive Infections during a COVID-19 Case Surge. Antimicrob. Agents Chemother. 2021, 65, AAC0114621. [CrossRef] [PubMed]

25. Magnasco, L.; Mikulska, M.; Giacobbe, D.; Taramasso, L.; Vena, A.; Dentone, C.; Dettori, S.; Tutino, S.; Labate, L.; Di Pilato, V.; et al. Spread of Carbapenem-Resistant Gram-Negatives and Candida auris During the COVID-19 Pandemic in Critically Ill Patients: One Step Back in Antimicrobial Stewardship? Microorganisms 2021, 9, 95. [CrossRef]

26. Rodriguez, J.Y.; Le Pape, P.; Lopez, O.; Esquea, K.; Labiosa, A.L.; Alvarez-Moreno, C. Candida auris: A latent threat to critically ill patients with COVID-19. Clin. Infect. Dis. 2020, 18, ciaa1595. [CrossRef]

27. Chowdhary, A.; Tarai, B.; Singh, A.; Sharma, A. Multidrug-Resistant Candida auris Infections in Critically Ill Coronavirus Disease Patients, India, April-July 2020. Emerg. Infect. Dis. 2020, 26, 2694-2696. [CrossRef]

28. Villanueva-Lozano, H.; Treviño-Rangel, R.D.J.; González, G.M.; Ramírez-Elizondo, M.T.; Lara-Medrano, R.; Aleman-Bocanegra, M.C.; Guajardo-Lara, C.E.; Gaona-Chávez, N.; Castilleja-Leal, F.; Torre-Amione, G.; et al. Outbreak of Candida auris infection in a COVID-19 hospital in Mexico. Clin. Microbiol. Infect. 2021, 27, 813-816. [CrossRef] 
29. Allaw, F.; Zahreddine, N.K.; Ibrahim, A.; Tannous, J.; Taleb, H.; Bizri, A.; Dbaibo, G.; Kanj, S. First Candida auris Outbreak during a COVID-19 Pandemic in a Tertiary-Care Center in Lebanon. Pathogens 2021, 10, 157. [CrossRef]

30. de Almeida, J.; Francisco, E.; Hagen, F.; Brandão, I.; Pereira, F.; Dias, P.P.; Costa, M.D.M.; Jordão, R.D.S.; de Groot, T.; Colombo, A. Emergence of Candida auris in Brazil in a COVID-19 Intensive Care Unit. J. Fungi 2021, 7, 220. [CrossRef] [PubMed]

31. Pemán, J.; Ruiz-Gaitán, A.; García-Vidal, C.; Salavert, M.; Ramírez, P.; Puchades, F.; García-Hita, M.; Alastruey-Izquierdo, A.; Quindós, G. Fungal co-infection in COVID-19 patients: Should we be concerned? Rev. Iberoam. Micol. 2020, 37, 41-46. [CrossRef] [PubMed]

32. European Center for Diseases Control (ECDC). Candida auris in Healthcare Settings-Europe (2016). Available online: http: / / ecdc.europa.eu/en/publications/_layouts/forms/Publication_Disp (accessed on 14 October 2021).

33. Public Health of England. Research and Analysis: Candida auris Identified in England. 2016. Available online: https://www. gov.uk/government/publications / candida-auris-emergence-in-england/candida-auris-identified-in-england (accessed on 14 October 2021).

34. Pan American Health Organization/World Health Organization. PAHO/WHO. Epidemiological Alerts and Reports: C. auris Outbreaks in Health Care Services. 2016. Available online: https:/ /www.paho.org/hq/dmdocuments/2016/2016-oct-3-phecandida-auris-epi-alert.pdf (accessed on 4 September 2021).

35. Chowdhary, A.; Sharma, A. The lurking scourge of multidrug resistant Candida auris in times of COVID-19 pandemic. J. Glob. Antimicrob. Resist. 2020, 22, 175-176. [CrossRef] [PubMed]

36. Lee, W.G.; Shin, J.H.; Uh, Y.; Kang, M.G.; Kim, S.H.; Park, K.H.; Jang, H.-C. First Three Reported Cases of Nosocomial Fungemia Caused by Candida auris. J. Clin. Microbiol. 2011, 49, 3139-3142. [CrossRef]

37. Sharma, M.; Chakrabarti, A. On the Origin of Candida auris: Ancestor, Environmental Stresses, and Antiseptics. mBio 2020, 11, e02102-20. [CrossRef]

38. Chow, N.A.; Muñoz, J.F.; Gade, L.; Berkow, E.L.; Li, X.; Welsh, R.M.; Forsberg, K.; Lockhart, S.R.; Adam, R.; Alanio, A.; et al. Tracing the Evolutionary History and Global Expansion of Candida auris Using Population Genomic Analyses. mBio 2020, 11, e03364-19. [CrossRef]

39. Chow, N.A.; De Groot, T.; Badali, H.; Abastabar, M.; Chiller, T.M.; Meis, J.F. Potential Fifth Clade of Candida auris, Iran, 2018. Emerg. Infect. Dis. 2019, 25, 1780-1781. [CrossRef]

40. Forsberg, K.; Woodworth, K.; Walters, M.; Berkow, E.L.; Jackson, B.; Chiller, T.; Vallabhaneni, S. Candida auris: The recent emergence of a multidrug-resistant fungal pathogen. Med. Mycol. 2018, 57, 1-12, Erratum in Med. Mycol. 2019, 57, e7. [CrossRef]

41. Casadevall, A.; Kontoyiannis, D.P.; Robert, V. On the Emergence of Candida auris: Climate Change, Azoles, Swamps, and Birds. mBio 2019, 10, e01397-19. [CrossRef] [PubMed]

42. Lamoth, F.; Kontoyiannis, D.P. The Candida auris Alert: Facts and Perspectives. J. Infect. Dis. 2017, 217, 516-520. [CrossRef]

43. Borman, A.M.; Szekely, A.; Johnson, E.M. Comparative Pathogenicity of United Kingdom Isolates of the Emerging Pathogen Candida auris and Other Key Pathogenic Candida Species. mSphere 2016, 1, e00189-16. [CrossRef] [PubMed]

44. Casadevall, A.; Kontoyiannis, D.P.; Robert, V. Environmental Candida auris and the Global Warming Emergence Hypothesis. $m B i o$ 2021, 12, e00360-21. [CrossRef]

45. Misseri, G.; Ippolito, M.; Cortegiani, A. Global warming "heating up" the ICU through Candida auris infections: The climate changes theory. Crit Care 2019, 23, 416. [CrossRef] [PubMed]

46. Casadevall, A. Fungi and the Rise of Mammals. PLoS Pathog. 2012, 8, e1002808. [CrossRef]

47. Robert, V.A.; Casadevall, A. Vertebrate Endothermy Restricts Most Fungi as Potential Pathogens. J. Infect. Dis. 2009, 200, 1623-1626. [CrossRef] [PubMed]

48. Arora, P.; Singh, P.; Wang, Y.; Yadav, A.; Pawar, K.; Singh, A.; Padmavati, G.; Xu, J.; Chowdhary, A. Environmental Isolation of Candida auris from the Coastal Wetlands of Andaman Islands, India. mBio 2021, 12, e03181-20. [CrossRef] [PubMed]

49. Muñoz, J.F.; Gade, L.; Chow, N.A.; Loparev, V.N.; Juieng, P.; Berkow, E.L.; Farrer, R.A.; Litvintseva, A.P.; Cuomo, C.A. Genomic insights into multidrug-resistance, mating and virulence in Candida auris and related emerging species. Nat. Commun. 2018, 9 , 1-13. [CrossRef]

50. Chybowska, A.D.; Childers, D.; Farrer, R.A. Nine Things Genomics Can Tell Us About Candida auris. Front. Genet. 2020, 11, 351. [CrossRef]

51. Cendejas-Bueno, E.; Kolecka, A.; Alastruey-Izquierdo, A.; Theelen, B.; Groenewald, M.; Kostrzewa, M.; Cuenca-Estrella, M.; Gómez-López, A.; Boekhout, T. Reclassification of the Candida haemulonii Complex as Candida haemulonii (C. haemulonii Group I), C. duobushaemulonii sp. nov. (C. haemulonii Group II), and C. haemulonii var. vulnera var. nov.: Three Multiresistant Human Pathogenic Yeasts. J. Clin. Microbiol. 2012, 50, 3641-3651. [CrossRef]

52. Kathuria, S.; Singh, P.K.; Sharma, C.; Prakash, A.; Masih, A.; Kumar, A.; Meis, J.F.; Chowdhary, A. Multidrug-Resistant Candida auris Misidentified as Candida haemulonii: Characterization by Matrix-Assisted Laser Desorption Ionization-Time of Flight Mass Spectrometry and DNA Sequencing and Its Antifungal Susceptibility Profile Variability by Vitek 2, CLSI Broth Microdilution, and Etest Method. J. Clin. Microbiol. 2015, 53, 1823-1830. [CrossRef] [PubMed]

53. Muñoz, J.F.; Welsh, R.M.; Shea, T.; Batra, D.; Gade, L.; Howard, D.; Rowe, L.A.; Meis, J.F.; Litvintseva, A.P.; Cuomo, C.A. Clade-specific chromosomal rearrangements and loss of subtelomeric adhesins in Candida auris. Genetics 2021, 218, iyab029. [CrossRef] [PubMed] 
54. Kim, M.; Shin, J.H.; Sung, H.; Lee, K.; Kim, E.; Ryoo, N.; Lee, J.; Jung, S.; Park, K.H.; Kee, S.J.; et al. Candida haemuloniiand Closely Related Species at 5 University Hospitals in Korea: Identification, Antifungal Susceptibility, and Clinical Features. Clin. Infect. Dis. 2009, 48, e57-e61. [CrossRef]

55. Rhodes, J.; Abdolrasouli, A.; Farrer, R.A.; Cuomo, C.A.; Aanensen, D.M.; Armstrong-James, D.; Fisher, M.C.; Schelenz, S. Genomic epidemiology of the UK outbreak of the emerging human fungal pathogen Candida auris. Emerg. Microbes Infect. 2018, 7, 1-12, Erratum in Emerg. Microbes. Infect. 2018, 7, 104. [CrossRef]

56. Kumar, A.; Sachu, A.; Mohan, K.; Vinod, V.; Dinesh, K.; Karim, S. Simple low cost differentiation of Candida auris from Candida haemulonii complex using CHROMagar Candida medium supplemented with Pal's medium. Rev. Iberoam. Micol. 2017, 34, 109-111. [CrossRef]

57. Chatterjee, S.; Alampalli, S.V.; Nageshan, R.K.; Chettiar, S.T.; Joshi, S.; Tatu, U.S. Draft genome of a commonly misdiagnosed multidrug resistant pathogen Candida auris. BMC Genom. 2015, 16, 1-16. [CrossRef]

58. Chowdhary, A.; Kumar, V.A.; Sharma, C.; Prakash, A.; Agarwal, K.; Babu, R.; Dinesh, K.R.; Karim, S.; Singh, S.K.; Hagen, F.; et al. Multidrug-resistant endemic clonal strain of Candida auris in India. Eur. J. Clin. Microbiol. Infect. Dis. 2013, 33, 919-926. [CrossRef]

59. Piedrahita, C.T.; Cadnum, J.L.; Jencson, A.L.; Shaikh, A.A.; Ghannoum, M.A.; Donskey, C.J. Environmental Surfaces in Healthcare Facilities are a Potential Source for Transmission of Candida auris and OtherCandidaSpecies. Infect. Control. Hosp. Epidemiol. 2017, 38, 1107-1109. [CrossRef]

60. Lone, S.A.; Ahmad, A. Candida auris-The growing menace to global health. Mycoses 2019, 62, 620-637. [CrossRef]

61. Garcia-Bustos, V.; Ruiz-Saurí, A.; Ruiz-Gaitán, A.; Sigona-Giangreco, I.A.; Cabañero-Navalon, M.D.; Sabalza-Baztán, O.; SalavertLletí, M.; Tormo, M.Á.; Pemán, J. Characterization of the Differential Pathogenicity of Candida auris in a Galleria mellonella Infection Model. Microbiol. Spectr. 2021, 3, e0001321. [CrossRef]

62. Sherry, L.; Ramage, G.; Kean, R.; Borman, A.; Johnson, E.M.; Richardson, M.D.; Rautemaa-Richardson, R. Biofilm-Forming Capability of Highly Virulent, Multidrug-Resistant Candida auris. Emerg. Infect. Dis. 2017, 23, 328-331. [CrossRef]

63. Romera, D.; Aguilera-Correa, J.-J.; García-Coca, M.; Mahillo-Fernández, I.; Viñuela-Sandoval, L.; García-Rodríguez, J.; Esteban, J. The Galleria mellonella infection model as a system to investigate the virulence of Candida auris strains. Pathog. Dis. 2020, 78, ftaa067. [CrossRef]

64. Muñoz, J.; Ramirez, L.; Dias, L.; Rivas, L.; Ramos, L.; Santos, A.; Taborda, C.; Parra-Giraldo, C. Pathogenicity Levels of Colombian Strains of Candida auris and Brazilian Strains of Candida haemulonii Species Complex in Both Murine and Galleria mellonella Experimental Models. J. Fungi 2020, 6, 104. [CrossRef]

65. Forgács, L.; Borman, A.; Prépost, E.; Tóth, Z.; Kardos, G.; Kovács, R.; Szekely, A.; Nagy, F.; Kovacs, I.; Majoros, L. Comparison of in vivo pathogenicity of four Candida auris clades in a neutropenic bloodstream infection murine model. Emerg. Microbes Infect. 2020, 9, 1160-1169. [CrossRef]

66. Carvajal, S.; Alvarado, M.; Rodríguez, Y.; Parra-Giraldo, C.; Varón, C.; Morales-López, S.; Rodríguez, J.; Gómez, B.; Escandón, P. Pathogenicity Assessment of Colombian Strains of Candida auris in the Galleria mellonella Invertebrate Model. J. Fungi $2021,7,401$. [CrossRef]

67. Hernando-Ortiz, A.; Mateo, E.; Perez-Rodriguez, A.; de Groot, P.W.; Quindós, G.; Eraso, E. Virulence of Candida auris from different clinical origins in Caenorhabditis elegans and Galleria mellonella host models. Virulence 2021, 12, 1063-1075. [CrossRef]

68. Alfouzan, W.; Dhar, R.; Albarrag, A.; Al-Abdely, H. The emerging pathogen Candida auris: A focus on the Middle-Eastern countries. J. Infect. Public Health 2019, 12, 451-459. [CrossRef]

69. Larkin, E.; Hager, C.; Chandra, J.; Mukherjee, P.K.; Retuerto, M.; Salem, I.; Long, L.; Isham, N.; Kovanda, L.; Borroto-Esoda, K.; et al. The Emerging Pathogen Candida auris: Growth Phenotype, Virulence Factors, Activity of Antifungals, and Effect of SCY-078, a Novel Glucan Synthesis Inhibitor, on Growth Morphology and Biofilm Formation. Antimicrob. Agents Chemother. 2017, 61, e02396-16. [CrossRef]

70. Hirayama, T.; Miyazaki, T.; Ito, Y.; Wakayama, M.; Shibuya, K.; Yamashita, K.; Takazono, T.; Saijo, T.; Shimamura, S.; Yamamoto, K.; et al. Virulence assessment of six major pathogenic Candida species in the mouse model of invasive candidiasis caused by fungal translocation. Sci. Rep. 2020, 10, 1-10. [CrossRef]

71. Borman, A.M. Of mice and men and larvae: Galleria mellonella to model the early host-pathogen interactions after fungal infection. Virulence 2017, 9, 9-12. [CrossRef]

72. Marcos-Zambrano, L.; Bordallo-Cardona, M.; Borghi, E.; Falleni, M.; Tosi, D.; Muñoz, P.; Escribano, P.; Guinea, J. Candida isolates causing candidemia show different degrees of virulence in Galleria mellonella. Med. Mycol. 2019, 58, 83-92. [CrossRef]

73. Chowdhary, A.; Sharma, C.; Duggal, S.; Agarwal, K.; Prakash, A.; Singh, P.K.; Jain, S.; Kathuria, S.; Randhawa, H.S.; Hagen, F.; et al. New Clonal Strain of Candida auris, Delhi, India. Emerg. Infect. Dis. 2013, 19, 1670-1673. [CrossRef]

74. Azar, M.M.; Turbett, S.E.; Fishman, J.A.; Pierce, V.M. Donor-Derived Transmission of Candida auris During Lung Transplantation. Clin. Infect. Dis. 2017, 65, 1040-1042. [CrossRef]

75. Yue, H.; Bing, J.; Zheng, Q.; Zhang, Y.; Hu, T.; Du, H.; Wang, H.; Huang, G. Filamentation in Candida auris, an emerging fungal pathogen of humans: Passage through the mammalian body induces a heritable phenotypic switch. Emerg. Microbes Infect. 2018, 7, 1-13. [CrossRef]

76. Bravo Ruiz, G.; Ross, Z.K.; Gow, N.A.R.; Lorenz, A. Pseudohyphal Growth of the Emerging Pathogen Candida auris Is Triggered by Genotoxic Stress through the S Phase Checkpoint. mSphere 2020, 5, e00151-20. [CrossRef] [PubMed] 
77. Fan, S.; Yue, H.; Zheng, Q.; Bing, J.; Tian, S.; Chen, J.; Ennis, C.L.; Nobile, C.J.; Huang, G.; Du, H. Filamentous growth is a general feature of Candida auris clinical isolates. Med. Mycol. 2021, 59, 734-740. [CrossRef] [PubMed]

78. Tian, S.; Rong, C.; Nian, H.; Li, F.; Chu, Y.; Cheng, S.; Shang, H. First cases and risk factors of super yeast Candida auris infection or colonization from Shenyang, China. Emerg. Microbes Infect. 2018, 7, 1-9. [CrossRef]

79. Wang, X.; Bing, J.; Zheng, Q.; Zhang, F.; Liu, J.; Yue, H.; Tao, L.; Du, H.; Wang, Y.; Wang, H.; et al. The first isolate of Candida auris in China: Clinical and biological aspects. Emerg. Microbes Infect. 2018, 7, 1-9. [CrossRef]

80. Sarma, S.; Kumar, N.; Govil, D.; Ali, T.; Mehta, Y.; Rattan, A. Candidemia caused by amphotericin B and Fluconazole resistant Candida auris. Indian J. Med. Microbiol. 2013, 31, 90-91. [CrossRef] [PubMed]

81. Khatamzas, E.; Madder, H.; Jeffery, K. Neurosurgical device-associated infections due to Candida auris - Three cases from a single tertiary center. J. Infect. 2019, 78, 409-421. [CrossRef]

82. Ruiz Gaitán, A.C.; Moret, A.; López Hontangas, J.L.; Molina, J.M.; Aleixandre López, A.I.; Cabezas, A.H.; Mollar Maseres, J.; Arcas, R.C.; Gómez Ruiz, M.D.; Chiveli, M.Á.; et al. Nosocomial fungemia by Candida auris: First four reported cases in continental Europe. Rev. Iberoam Micol. 2017, 34, 23-27. [CrossRef]

83. Heath, C.H.; Dyer, J.R.; Pang, S.; Coombs, G.W.; Gardam, D.J. Candida auris Sternal Osteomyelitis in a Man from Kenya Visiting Australia, 2015. Emerg. Infect. Dis. 2019, 25, 192-194. [CrossRef]

84. Alatoom, A.; Sartawi, M.; Lawlor, K.; AbdelWareth, L.; Thomsen, J.; Nusair, A.; Mirza, I. Persistent candidemia despite appropriate fungal therapy: First case of Candida auris from the United Arab Emirates. Int. J. Infect. Dis. 2018, 70, 36-37. [CrossRef]

85. Sharp, A.; Borman, A.; Perera, N.; Randle, M.; Braham, S.; Taori, S.; Charlett, A.; Guy, R.; Muller-Pebody, B.; Manuel, R.; et al. Assessing routine diagnostic methods for detecting Candida auris in England. J. Infect. 2018, 77, 448-454. [CrossRef]

86. Durante, A.J.; Maloney, M.H.; Leung, V.H.; Razeq, J.H.; Banach, D.B. Challenges in identifying Candida auris in hospital clinical laboratories: A need for hospital and public health laboratory collaboration in rapid identification of an emerging pathogen. Infect. Control. Hosp. Epidemiol. 2018, 39, 1015-1016. [CrossRef] [PubMed]

87. Clancy, C.J.; Nguyen, M.H. Emergence of Candida auris: An International Call to Arms. Clin. Infect. Dis. 2016, 64, 141-143. [CrossRef] [PubMed]

88. Dewaele, K.; Lagrou, K.; Frans, J.; Hayette, M.-P.; Vernelen, K. Hospital Laboratory Survey for Identification of Candida auris in Belgium. J. Fungi 2019, 5, 84. [CrossRef] [PubMed]

89. Mahmoudi, S.; Afshari, S.A.K.; Gharehbolagh, S.A.; Mirhendi, H.; Makimura, K. Methods for identification of Candida auris, the yeast of global public health concern: A review. J. Mycol. Med. 2019, 29, 174-179. [CrossRef]

90. Sharma, C.; Kumar, N.; Meis, J.F.; Pandey, R.; Chowdhary, A. Draft Genome Sequence of a Fluconazole-Resistant Candida auris Strain from a Candidemia Patient in India. Genome Announc. 2015, 3, e00722-15. [CrossRef]

91. Alvarado, M.; Álvarez, J.B.; Lockhart, S.R.; Valentín, E.; Ruiz-Gaitán, A.C.; Eraso, E.; De Groot, P.W. Identification of Candida auris and related species by multiplex PCR based on unique GPI protein-encoding genes. Mycoses 2020, 64, 194-202. [CrossRef]

92. Martínez-Murcia, A.; Navarro, A.; Bru, G.; Chowdhary, A.; Hagen, F.; Meis, J.F. Internal validation of GPS ${ }^{\mathrm{TM}}$ MONODOSE CanAur dtec-qPCR kit following the UNE/EN ISO/IEC 17025:2005 for detection of the emerging yeast Candida auris. Mycoses 2018, 61, 877-884. [CrossRef]

93. Sattler, J.; Noster, J.; Brunke, A.; Plum, G.; Wiegel, P.; Kurzai, O.; Meis, J.; Hamprecht, A. Comparison of Two Commercially Available qPCR Kits for the Detection of Candida auris. J. Fungi 2021, 7, 154. [CrossRef]

94. de Jong, A.W.; Dieleman, C.; Carbia, M.; Tap, R.M.; Hagen, F. Performance of Two Novel Chromogenic Media for the Identification of Multidrug-Resistant Candida auris Compared with Other Commercially Available Formulations. J. Clin. Microbiol. 2021, 59, e03220-20. [CrossRef]

95. Sigona-Giangreco, I.A.; Garcia-Hita, M.; Ruiz-Gaitan, A.; Valentín-Gómez, E.; Garcia-Bustos, V.; Giner-Almaraz, M.; de Groot, P.; Peman, J. Usefulness of chromogenic media for presumptive identification of Candida auris. Material Intended for Publication; Unpublished work.

96. Calderone, R.A.; Fonzi, W.A. Virulence factors of Candida albicans. Trends Microbiol. 2001, 9, 327-335. [CrossRef]

97. Pharkjaksu, S.; Boonmee, N.; Mitrpant, C.; Ngamskulrungroj, P. Immunopathogenesis of Emerging Candida auris and Candida haemulonii Strains. J. Fungi 2021, 7, 725. [CrossRef] [PubMed]

98. Rhodes, J.; Fisher, M.C. Global epidemiology of emerging Candida auris. Curr. Opin. Microbiol. 2019, 52, 84-89. [CrossRef]

99. Lima, S.L.; Rossato, L.; Melo, A.S.D.A. Evaluation of the potential virulence of Candida haemulonii species complex and Candida auris isolates in Caenorhabditis elegans as an in vivo model and correlation to their biofilm production capacity. Microb. Pathog. 2020, 148, 104461. [CrossRef] [PubMed]

100. Wurster, S.; Bandi, A.; Beyda, N.D.; Albert, N.D.; Raman, N.M.; Raad, I.I.; Kontoyiannis, D.P. Drosophila melanogaster as a model to study virulence and azole treatment of the emerging pathogen Candida auris. J. Antimicrob. Chemother. 2019, 74, 1904-1910. [CrossRef] [PubMed]

101. Brown, J.L.; Delaney, C.; Short, B.; Butcher, M.C.; McKloud, E.; Williams, C.; Kean, R.; Ramage, G. Candida auris Phenotypic Heterogeneity Determines Pathogenicity In Vitro. mSphere 2020, 5, e00371-20. [CrossRef] [PubMed]

102. Tsai, C.J.-Y.; Loh, J.M.S.; Proft, T. Galleria mellonella infection models for the study of bacterial diseases and for antimicrobial drug testing. Virulence 2016, 7, 214-229. [CrossRef]

103. Gago, S.; Garcia-Rodas, R.; Cuesta, I.; Mellado, E.; Alastruey-Izquierdo, A. Candida parapsilosis, Candida orthopsilosis, and Candida metapsilosisvirulence in the non-conventional hostGalleria mellonella. Virulence 2013, 5, 278-285. [CrossRef] 
104. Perdoni, F.; Falleni, M.; Tosi, D.; Cirasola, D.; Romagnoli, S.; Braidotti, P.; Clementi, E.; Bulfamante, G.; Borghi, E. A histological procedure to study fungal infection in the wax moth Galleria mellonella. Eur. J. Histochem. 2014, 58, 2428. [CrossRef]

105. Ames, L.; Duxbury, S.; Pawlowska, B.; Ho, H.-L.; Haynes, K.; Bates, S. Galleria mellonella as a host model to study Candida glabrata virulence and antifungal efficacy. Virulence 2017, 8, 1909-1917. [CrossRef]

106. Frenkel, M.; Mandelblat, M.; Alastruey-Izquierdo, A.; Mendlovic, S.; Semis, R.; Segal, E. Pathogenicity of Candida albicans isolates from bloodstream and mucosal candidiasis assessed in mice and Galleria mellonella. J. Mycol. Med. 2016, 26, 1-8. [CrossRef]

107. Mesa-Arango, A.C.; Forastiero, A.; Bernal-Martínez, L.; Cuenca-Estrella, M.; Mellado, E.; Zaragoza, O. The non-mammalian hostGalleria mellonellacan be used to study the virulence of the fungal pathogenCandida tropicalisand the efficacy of antifungal drugs during infection by this pathogenic yeast. Med. Mycol. 2013, 51, 461-472. [CrossRef]

108. Szekely, A.; Borman, A.M.; Johnson, E.M. Candida auris Isolates of the Southern Asian and South African Lineages Exhibit Different Phenotypic and Antifungal Susceptibility Profiles In Vitro. J. Clin. Microbiol. 2019, 57, e02055-18. [CrossRef]

109. Abdolrasouli, A.; Armstrong-James, D.; Ryan, L.; Schelenz, S. In vitro efficacy of disinfectants utilised for skin decolonisation and environmental decontamination during a hospital outbreak with Candida auris. Mycoses 2017, 60, 758-763. [CrossRef]

110. Singh, R.; Kaur, M.; Chakrabarti, A.; Shankarnarayan, S.A.; Rudramurthy, S.M. Biofilm formation by Candida auris isolated from colonising sites and candidemia cases. Mycoses 2019, 62, 706-709. [CrossRef] [PubMed]

111. Bhattacharya, S.; Holowka, T.; Orner, E.P.; Fries, B.C. Gene Duplication Associated with Increased Fluconazole Tolerance in Candida auris cells of Advanced Generational Age. Sci. Rep. 2019, 9, 1-13. [CrossRef]

112. Mba, I.E.; Nweze, E.I. Mechanism of Candida pathogenesis: Revisiting the vital drivers. Eur. J. Clin. Microbiol. Infect. Dis. 2020, 39, 1797-1819. [CrossRef] [PubMed]

113. Staniszewska, M.; Monika, S. Virulence Factors in Candida species. Curr. Protein Pept. Sci. 2020, 21, 313-323. [CrossRef] [PubMed]

114. Jabeen, K.; Mal, P.B.; Tharwani, A.; Hashmi, M.; Farooqi, J. Persistence of Candida auris on latex and nitrile gloves with transmission to sterile urinary cathetersł. Med. Mycol. 2019, 58, 128-132. [CrossRef] [PubMed]

115. Castro, L.A.; Álvarez, M.I.; Giusiano, G.; Martínez, E. Candida auris infection in the central catheter of a patient without sepsis symptoms. Colomb. Medica 2019, 50, 293-298. [CrossRef] [PubMed]

116. Horton, M.V.; Johnson, C.J.; Kernien, J.F.; Patel, T.D.; Lam, B.C.; Cheong, J.Z.A.; Meudt, J.J.; Shanmuganayagam, D.; Kalan, L.R.; Nett, J.E. Candida auris Forms High-Burden Biofilms in Skin Niche Conditions and on Porcine Skin. mSphere 2020, 5, e00910-19. [CrossRef]

117. Kean, R.; Delaney, C.; Sherry, L.; Borman, A.; Johnson, E.M.; Richardson, M.D.; Rautemaa-Richardson, R.; Williams, C.; Ramage, G. Transcriptome Assembly and Profiling of Candida auris Reveals Novel Insights into Biofilm-Mediated Resistance. mSphere 2018, 3, e00334-18. [CrossRef]

118. Kean, R.; Brown, J.; Gulmez, D.; Ware, A.; Ramage, G. Candida auris: A Decade of Understanding of an Enigmatic Pathogenic Yeast. J. Fungi 2020, 6, 30. [CrossRef]

119. Kean, R.; Ramage, G. Combined Antifungal Resistance and Biofilm Tolerance: The Global Threat of Candida auris. mSphere 2019, 4, e00458-19. [CrossRef]

120. Dominguez, E.G.; Zarnowski, R.; Choy, H.L.; Zhao, M.; Sanchez, H.; Nett, J.E.; Andes, D.R. Conserved Role for Biofilm Matrix Polysaccharides in Candida auris Drug Resistance. mSphere. 2019, 2, e00680-18. [CrossRef]

121. Kumar, D.; Banerjee, T.; Pratap, C.B.; Tilak, R. Itraconazole-resistant Candida auris with phospholipase, proteinase and hemolysin activity from a case of vulvovaginitis. J. Infect. Dev. Ctries. 2015, 9, 435-437. [CrossRef] [PubMed]

122. Johnson, C.J.; Davis, J.M.; Huttenlocher, A.; Kernien, J.F.; Nett, J.E. Emerging Fungal Pathogen Candida auris Evades Neutrophil Attack. mBio 2018, 9, e01403-18. [CrossRef]

123. Chaabane, F.; Graf, A.; Jequier, L.; Coste, A.T. Review on Antifungal Resistance Mechanisms in the Emerging Pathogen Candida auris. Front. Microbiol. 2019, 10, 2788. [CrossRef]

124. Kordalewska, M.; Lee, A.; Park, S.; Berrio, I.; Chowdhary, A.; Zhao, Y.; Perlin, D.S. Understanding Echinocandin Resistance in the Emerging Pathogen Candida auris. Antimicrob. Agents Chemother. 2018, 62, e00238-18. [CrossRef] [PubMed]

125. Zhu, Y.; O’Brien, B.; Leach, L.; Clarke, A.; Bates, M.; Adams, E.; Ostrowsky, B.; Quinn, M.; Dufort, E.; Southwick, K.; et al. Laboratory Analysis of an Outbreak of Candida auris in New York from 2016 to 2018: Impact and Lessons Learned. J. Clin. Microbiol. 2020, 58, e01503-19. [CrossRef]

126. Chowdhary, A.; Prakash, A.; Sharma, C.; Kordalewska, M.; Kumar, A.; Sarma, S.; Tarai, B.; Singh, A.; Upadhyaya, G.; Upadhyay, S.; et al. A multicentre study of antifungal susceptibility patterns among 350 Candida auris isolates (2009-17) in India: Role of the ERG11 and FKS1 genes in azole and echinocandin resistance. J. Antimicrob. Chemother. 2018, 73, 891-899. [CrossRef]

127. Rodrigues, M.L. The Multifunctional Fungal Ergosterol. mBio 2018, 9, e01755-18. [CrossRef] [PubMed]

128. Yadav, A.; Singh, A.; Wang, Y.; Haren, M.; Singh, A.; de Groot, T.; Meis, J.; Xu, J.; Chowdhary, A. Colonisation and Transmission Dynamics of Candida auris among Chronic Respiratory Diseases Patients Hospitalised in a Chest Hospital, Delhi, India: A Comparative Analysis of Whole Genome Sequencing and Microsatellite Typing. J. Fungi 2021, 7, 81. [CrossRef]

129. Rybak, J.M.; Doorley, L.A.; Nishimoto, A.T.; Barker, K.S.; Palmer, G.E.; Rogers, P.D. Abrogation of Triazole Resistance upon Deletion of CDR1 in a Clinical Isolate of Candida auris. Antimicrob. Agents Chemother. 2019, 63, e00057-19. [CrossRef]

130. Rybak, J.M.; Muñoz, J.F.; Barker, K.S.; Parker, J.E.; Esquivel, B.D.; Berkow, E.L.; Lockhart, S.R.; Gade, L.; Palmer, G.E.; White, T.C.; et al. Mutations in TAC1B: A Novel Genetic Determinant of Clinical Fluconazole Resistance in Candida auris. mBio 2020, 11, e00365-20. [CrossRef] [PubMed] 
131. Sharma, D.; Paul, R.A.; Chakrabarti, A.; Bhattacharya, S.; Soman, R.; Shankarnarayan, A.; Chavan, D.; Shreya, S.; Das, P.; Kaur, $\mathrm{H}$.; et al. Caspofungin resistance in Candia auris due to mutations in Fks1 with adjunctive role of chitin and key cell wall stress response pathway genes. bioRxiv 2020. preprint. [CrossRef]

132. Hope, W.W.; Tabernero, L.; Denning, D.W.; Anderson, M.J. Molecular Mechanisms of Primary Resistance to Flucytosine in Candida albicans. Antimicrob. Agents Chemother. 2004, 48, 4377-4386. [CrossRef]

133. Bhattacharya, S.; Bouklas, T.; Fries, B.C. Replicative Aging in Pathogenic Fungi. J. Fungi 2020, 7, 6. [CrossRef] [PubMed]

134. Sekyere, J.O. Candida auris: A systematic review and meta-analysis of current updates on an emerging multidrug-resistant pathogen. Microbiologyopen 2018, 7, e00578. [CrossRef]

135. Ahmad, S.; Alfouzan, W. Candida auris: Epidemiology, Diagnosis, Pathogenesis, Antifungal Susceptibility, and Infection Control Measures to Combat the Spread of Infections in Healthcare Facilities. Microorganisms 2021, 9, 807. [CrossRef] [PubMed]

136. Cortegiani, A.; Misseri, G.; Fasciana, T.; Giammanco, A.; Giarratano, A.; Chowdhary, A. Epidemiology, clinical characteristics, resistance, and treatment of infections by Candida auris. J. Intensiv. Care 2018, 6, 1-13. [CrossRef] [PubMed]

137. Caceres, D.H.; Forsberg, K.; Welsh, R.M.; Sexton, D.J.; Lockhart, S.R.; Jackson, B.R.; Chiller, T. Candida auris: A Review of Recommendations for Detection and Control in Healthcare Settings. J. Fungi 2019, 5, 111. [CrossRef]

138. Rossow, J.; Ostrowsky, B.; Adams, E.; Greenko, J.; McDonald, R.; Vallabhaneni, S.; Forsberg, K.; Perez, S.; Lucas, T.; Alroy, K.A.; et al. Factors Associated With Candida auris Colonization and Transmission in Skilled Nursing Facilities With Ventilator Units, New York, 2016-2018. Clin. Infect. Dis. 2020, 72, e753-e760. [CrossRef] [PubMed]

139. Spivak, E.S.; Hanson, K.E. Candida auris: An Emerging Fungal Pathogen. J. Clin. Microbiol. 2018, 56, e01588-17. [CrossRef]

140. Abe, M.; Katano, H.; Nagi, M.; Higashi, Y.; Sato, Y.; Kikuchi, K.; Hasegawa, H.; Miyazaki, Y. Potency of gastrointestinal colonization and virulence of Candida auris in a murine endogenous candidiasis. PLoS ONE 2020, 15, e0243223. [CrossRef]

141. Day, A.M.; McNiff, M.M.; Dantas, A.D.S.; Gow, N.A.R.; Quinn, J. Hog1 Regulates Stress Tolerance and Virulence in the Emerging Fungal Pathogen Candida auris. mSphere 2018, 3, e00506-18. [CrossRef]

142. Biagi, M.J.; Wiederhold, N.P.; Gibas, C.; Wickes, B.; Lozano, V.; Bleasdale, S.C.; Danziger, L. Development of High-Level Echinocandin Resistance in a Patient With Recurrent Candida auris Candidemia Secondary to Chronic Candiduria. Open Forum Infect. Dis. 2019, 6, ofz262. [CrossRef]

143. Vallabhaneni, S.; Kallen, A.; Tsay, S.; Chow, N.; Welsh, R.; Kerins, J.; Kemble, S.K.; Pacilli, M.; Black, S.R.; Landon, E.; et al. Investigation of the First Seven Reported Cases of Candida auris, a Globally Emerging Invasive, Multidrug-Resistant Fungus-United States, May 2013-August 2016. Morb. Mortal. Weekly Rep. 2016, 65, 1234-1237. [CrossRef]

144. Pemán, J.; Ruiz-Gaitán, A. Candidemia from urinary tract source: The challenge of candiduria. Hosp. Pract. 2018, 46, 243-245. [CrossRef]

145. Hata, D.J.; Humphries, R.; Lockhart, S.R. Candida auris: An Emerging Yeast Pathogen Posing Distinct Challenges for Laboratory Diagnostics, Treatment, and Infection Prevention. Arch. Pathol. Lab. Med. 2019, 144, 107-114. [CrossRef]

146. Mamtani, S.S.; Aljanabi, N.M.; Rauniyar, R.P.G.; Acharya, A.; Malik, B.H. Candida Endocarditis: A Review of the Pathogenesis, Morphology, Risk Factors, and Management of an Emerging and Serious Condition. Cureus 2020, 12, e6695. [CrossRef]

147. Morales-López, S.E.; Parra-Giraldo, C.M.; Ceballos-Garzón, A.; Martínez, H.P.; Rodríguez, G.J.; Álvarez-Moreno, C.A.; Rodríguez, J.Y. Invasive Infections with Multidrug-Resistant Yeast Candida auris, Colombia. Emerg Infect Dis. 2017, 23, 162-164. [CrossRef]

148. Ben-Ami, R.; Berman, J.; Novikov, A.; Bash, E.; Shachor-Meyouhas, Y.; Zakin, S.; Maor, Y.; Tarabia, J.; Schechner, V.; Adler, A.; et al. Multidrug-Resistant Candida haemuloniiand and C. auris, Tel Aviv, Israel. Emerg. Infect. Dis. 2017, 23, 195-203. [CrossRef]

149. Sexton, D.J.; Bentz, M.L.; Welsh, R.M.; Litvintseva, A.P. Evaluation of a new T2 Magnetic Resonance assay for rapid detection of emergent fungal pathogen Candida auris on clinical skin swab samples. Mycoses 2018, 61, 786-790. [CrossRef]

150. Supreeth, S.; Al Ghafri, K.A.; Jayachandra, R.K.; Al Balushi, Z.Y. First Report of Candida auris Spondylodiscitis in Oman: A Rare Presentation. World Neurosurg. 2019, 135, 335-338. [CrossRef]

151. Garcia-Bustos, V.; Salavert, M.; Ruiz-Gaitán, A.C.; Cabañero-Navalon, M.D.; Sigona-Giangreco, I.A.; Pemán, J. A clinical predictive model of candidaemia by Candida auris in previously colonized critically ill patients. Clin. Microbiol. Infect. 2020, 2020 26, 1507-1513. [CrossRef]

152. Sayeed, M.A.; Farooqi, J.; Jabeen, K.; Mahmood, S.F. Comparison of risk factors and outcomes of Candida auris candidemia with non-Candida auris candidemia: A retrospective study from Pakistan. Med. Mycol. 2019, 58, 721-729. [CrossRef] [PubMed]

153. Sarma, S.; Upadhyay, S. Current perspective on emergence, diagnosis and drug resistance in Candida auris. Infect. Drug Resist. 2017, 10, 155-165. [CrossRef] [PubMed]

154. Černáková, L.; Roudbary, M.; Brás, S.; Tafaj, S.; Rodrigues, C. Candida auris: A Quick Review on Identification, Current Treatments, and Challenges. Int. J. Mol. Sci. 2021, 22, 4470. [CrossRef] [PubMed]

155. Centers for Disease Control and Prevention (CDC). Recommendations for Treatment of Candida auris Infections. 2021. Available online: https: / www.cdc.gov / fungal/candida-auris/c-auris-treatment.html (accessed on 16 September 2021).

156. Bidaud, A.L.; Botterel, F.; Chowdhary, A.; Dannaoui, E. In Vitro Antifungal Combination of Flucytosine with Amphotericin B, Voriconazole, or Micafungin against Candida auris Shows No Antagonism. Antimicrob. Agents Chemother. 2019, 63, e01393-19. [CrossRef]

157. Rudramurthy, S.M.; Colley, T.; Abdolrasouli, A.; Ashman, J.; Dhaliwal, M.; Kaur, H. In vitro antifungal activity of a novel topical triazole PC945 against emerging yeast Candida auris. J. Antimicrob. Chemother. 2019, 74, 2943-2949. [CrossRef] 
158. Eldesouky, H.E.; Li, X.; Abutaleb, N.; Mohammad, H.; Seleem, M. Synergistic interactions of sulfamethoxazole and azole antifungal drugs against emerging multidrug-resistant Candida auris. Int. J. Antimicrob. Agents 2018, 52, 754-761. [CrossRef]

159. Eldesouky, H.E.; Salama, E.A.; Lanman, N.A.; Hazbun, T.R.; Seleem, M.N. Potent Synergistic Interactions between Lopinavir and Azole Antifungal Drugs against Emerging Multidrug-Resistant Candida auris. Antimicrob. Agents Chemother. 2020, 65, e00684-20. [CrossRef]

160. Eldesouky, H.E.; Lanman, N.A.; Hazbun, T.R.; Seleem, M.N. Aprepitant, an antiemetic agent, interferes with metal ion homeostasis of Candida auris and displays potent synergistic interactions with azole drugs. Virulence 2020, 11, 1466-1481. [CrossRef]

161. De Oliveira, H.C.; Monteiro, M.C.; Rossi, S.A.; Pemán, J.; Ruiz-Gaitán, A.; Mendes-Giannini, M.J.S.; Mellado, E.; Zaragoza, O. Identification of Off-Patent Compounds That Present Antifungal Activity Against the Emerging Fungal Pathogen Candida auris. Front. Cell. Infect. Microbiol. 2019, 9, 83. [CrossRef] [PubMed]

162. Hager, C.L.; Larkin, E.L.; Long, L.; Abidi, F.Z.; Shaw, K.J.; Ghannoum, M.A. In Vitro and In Vivo Evaluation of the Antifungal Activity of APX001A/APX001 against Candida auris. Antimicrob. Agents Chemother. 2018, 62, e2319-17. [CrossRef] [PubMed]

163. Wiederhold, N.P.; Najvar, L.K.; Jaramillo, R.; Olivo, M.; Patterson, H.; Connell, A.; Fukuda, Y.; Mitsuyama, J.; Catano, G.; Patterson, T.F. The Novel Arylamidine T-2307 Demonstrates In Vitro and In Vivo Activity against Candida auris. Antimicrob. Agents Chemother. 2020, 64, e02198-19. [CrossRef] [PubMed]

164. Arendrup, M.C.; Jørgensen, K.M.; Hare, R.K.; Chowdhary, A. In Vitro Activity of Ibrexafungerp (SCY-078) against Candida auris Isolates as Determined by EUCAST Methodology and Comparison with Activity against C. albicans and C. glabrata and with the Activities of Six Comparator Agents. Antimicrob. Agents Chemother. 2020, 64, e02136-19. [CrossRef] [PubMed]

165. Fuchs, F.; Hof, H.; Hofmann, S.; Kurzai, O.; Meis, J.F.; Hamprecht, A. Antifungal activity of nitroxoline against Candida auris isolates. Clin. Microbiol. Infect. 2021, in press. [CrossRef] [PubMed]

166. Wiederhold, N.P.; Lockhart, S.R.; Najvar, L.K.; Berkow, E.L.; Jaramillo, R.; Olivo, M.; Garvey, E.P.; Yates, C.M.; Schotzinger, R.J.; Catano, G.; et al. The Fungal Cyp51-Specific Inhibitor VT-1598 Demonstrates In Vitro and In Vivo Activity against Candida auris. Antimicrob. Agents Chemother. 2019, 63, e02233-18. [CrossRef]

167. Shaban, S.; Patel, M.; Ahmad, A. Improved efficacy of antifungal drugs in combination with monoterpene phenols against Candida auris. Sci. Rep. 2020, 10, 1-8. [CrossRef]

168. Dal Mas, C.; Rossato, L.; Shimizu, T.; Oliveira, E.B.; da Silva Junior, P.I.; Meis, J.F.; Colombo, A.L.; Hayashi, M.A.F. Effects of the Natural Peptide Crotamine from a South American Rattlesnake on Candida auris, an Emergent Multidrug Antifungal Resistant Human Pathogen. Biomolecules 2019, 9, 205. [CrossRef]

169. Srivastava, V.; Ahmad, A. Abrogation of pathogenic attributes in drug resistant Candida auris strains by farnesol. PLoS ONE 2020, 15, e0233102. [CrossRef] [PubMed]

170. Pathirana, R.U.; Friedman, J.; Norris, H.L.; Salvatori, O.; McCall, A.D.; Kay, J.; Edgerton, M. Fluconazole-Resistant Candida auris Is Susceptible to Salivary Histatin 5 Killing and to Intrinsic Host Defenses. Antimicrob. Agents Chemother. 2018, 62, e01872-17. [CrossRef] [PubMed]

171. Iyer, K.R.; Whitesell, L.; Porco, J.A.; Henkel, T.; Brown, L.E.; Robbins, N.; Cowen, L.E. Translation Inhibition by Rocaglates Activates a Species-Specific Cell Death Program in the Emerging Fungal Pathogen Candida auris. mBio 2020, 11, e03329-19. [CrossRef] [PubMed] 